\title{
How Entrepreneurs make sense of Lean Startup Approaches: Business Models as cognitive lenses to generate fast and frugal Heuristics
}

\author{
Article in press \\ Forthcoming in Technological Forecasting and Social Change
}

Please cite as:

Ghezzi, A. (2020). How Entrepreneurs make sense of Lean Startup Approaches: Business Models as cognitive lenses to generate fast and frugal Heuristics. Technological Forecasting and Social Change, Volume 161, December 2020, 120324, https://doi.org/10.1016/j.techfore.2020.120324

\author{
Antonio Ghezzi* \\ Politecnico di Milano, Department of Management, Economics and Industrial Engineering, Via \\ Lambruschini, 4/B, 20156 Milano, Italy. \\ E-mail : antonio1.ghezzi@polimi.it \\ * Corresponding author
}

\begin{abstract}
Short vitae
Antonio Ghezzi, Ph.D. is Associate Professor of Strategic Management and Entrepreneurship, and Head of the Hi-tech Startups and Space Economy applied research centers at the Department of Management, Economics and Industrial Engineering - Politecnico di Milano. His main research field is Strategy and Digital Entrepreneurship, with a focus on startups' business model design, innovation and validation, and the role of Lean Startup Approaches for experimentation. He is author of more than one hundred scientific journal articles (appearing in outlets such as Technological Forecasting and Social Change, International Journal of Management Reviews, Journal of Business Research, International Journal of Production Economics, Management Decision and R\&D Management), books, book chapters and conference proceedings.
\end{abstract}




\title{
How Entrepreneurs make sense of Lean Startup Approaches: Business Models as cognitive lenses to generate fast and frugal Heuristics
}

\begin{abstract}
The role of the business model (BM) as heuristics to support entrepreneurial and strategic problem solving at a cognitive level has been hinted at by extant literature, but left largely unexplored as of yet. This study is positioned in the emerging research on the cognitive individual microfoundations of Entrepreneurship and Strategy, and contributes to the discussion of how business models are used as heuristics, in the novel and relevant setting of Digital Entrepreneurship. We conducted a multiple case study on three digital startups that applied the emerging Lean Startup Approaches (LSAs) and embody technological development in their value proposition. We found that digital entrepreneurs applying LSAs as a systematic process to validate their business ideas rely on business models as cognitive lenses to make sense of LSAs and translate abstract guidelines into fast and frugal heuristics, in order to 'make do' with cognitive resource scarcity. These BM-generated heuristics in turn help entrepreneurs in the activities of: (i) making sense of entrepreneurial opportunities; (ii) formulating falsifiable hypotheses concerning their startups' viability; (iii) filtering, selecting and organizing fuzzy and incomplete external and internal information; (iv) designing multidimensional customer experiments and tests revolving around the notion of value, through Minimum Viable Business Models (MVBMs); ( $v$ ) prioritizing these experiments and tests to validate their early BM through analogical arguments; and (vi) processing the learning they obtain from experiments, and concretizing it in the form of BM pivots. We also provide empirically-driven insight on an integrative set of cognitive processes - namely (1) cognitive imprinting, (2) common language transfer; (3) attention intensity and (4) scientific and experimental cognition - that mold and blend together the BM-generated heuristics and explain how they are learnt, transferred, enacted, and how they persistently enable a cognitive transition to the application of a scientific method to Entrepreneurship based on more sophisticated experiments and metrics.
\end{abstract}

Keywords: Business Model; Heuristic; Lean Startup Approaches; Microfoundations; Entrepreneurship; Experimentation; Digital Entrepreneurship; Scientific method

«Non sunt multiplicanda entia sine necessitate» (Entities are not to be multiplied without necessity)

William of Ockham (c. 1287-1347)

\section{Introduction}

The question of how entrepreneurs make decisions in complex environments, with limited information and resources at hand, has long been puzzling academics and practitioners.

Facing an uncertain decision-making context, entrepreneurs are often asked to plan for the unexpected, act to leverage contingencies as they arise (Yang et al., 2019) and "make do" with their scarce resources endowment, in line with the effectuation (Sarasvathy, 2001) and entrepreneurial bricolage approaches (Baker and Nelson, 2005). 
Put differently, entrepreneurs have to make satisfactorily good decisions is severely constrained conditions.

These archetypal circumstances in entrepreneurship are even amplified by additional context-specific determinants, like the embryonic stage in the startup's lifecycle and the digital essence of its value proposition. In their early stage of development, startups frequently undergo several and severe changes in their content and structure (Ghezzi and Cavallo, 2020) and entrepreneurs are forced to make decisions and subsequently take action by bootstrapping limited human, social, financial and technological capital. In addition to this, digital startups (Nambisan, 2017) have to constantly scan for emerging digital affordances - i.e. potentialities for new functions and uses (Autio et al., 2018) - and quickly define whether to include or exclude them from their offer: these decisions are themselves often taken quickly and frugally, without fine-grained information and structured analysis.

Such challenging setting called for new models and tools that could help entrepreneurs in possibly simplifying their action.

The Lean Startup Approaches or LSAs (Blank, 2007; Ries, 2011; Blank and Dorf, 2012; Blank, 2013) emerged to address this call and help digital entrepreneurs face the perilous task of developing their startup around a business idea.

LSAs are praised for their pragmatic, hands-on stance towards entrepreneurial problem solving and decision making (Frederiksen and Brem, 2017; Ghezzi, 2019; Yang et al., 2019).

More in detail, LSAs were conceived to support the entrepreneurial activity of experimenting and testing the startup's value architecture, intended as the composition of its value creation, value delivery and value capture logics (Teece, 2010; Foss and Saebi, 2018): in sum, LSAs support the process of a startup's business model (BM) validation (Bortolini et al., 2018; Silva et al., 2019). LSAs emerge from realizing that startups are ultimately a temporary business model looking for validation through market experimentation or "customer discovery" (Blank, 2007), whereas experiments are meant to understand whether the BM is suitable for scaling, or should instead be modified, pivoted or even dropped altogether according to the results of the experiments and customer feedback.

In their conception and enrollment, LSAs hence explicitly refer to and preach the use of the business model construct, which constitutes a way to translate a business idea shaped around an entrepreneurial opportunity into specific startup design parameters (e.g. Osterwalder and Pigneur, 2010): thus, according to the LSAs, the BM may allow to shift from fuzziness to pragmatism, and from complexity to simplicity.

Although the pragmatic adoption of LSAs encountered positive and widespread acceptance in the entrepreneurial community (Fredericksen and Brem, 2017), little research investigated and explored: (i) how entrepreneurs cognitively translate LSAs guidelines into actions; (ii) how the business model is used as a mental and cognitive entrepreneurial problem solving and decision making device in LSAs' application; and (iii) which logics and mechanisms are enacted in the process, as well as which benefits or drawbacks emerge.

As a result, a promising research avenue exists, embedded in the microfoundations of Entrepreneurship and Strategy (Minniti and Bygrave, 1999; Felin et al., 2015), which concerns how entrepreneurs cognitively approach LSAs and possibly use the business model within this emerging context to cognitively make do: that is, bricolage to manage the tensions coming from the realization that their individual cognition and 
computational power are themselves scarce resources in the act of exploring and realizing entrepreneurial opportunities.

In order to contribute to the debate and shed light on a largely unexplored area, this study builds on the business model literature and crosses it with the heuristics literature, where heuristics are defined as cognitive constructs and shortcuts emerging when information, time and processing capacity are constrained (Newell and Simon, 1972; Bingham and Eisenhardt, 2011; Loock and Hinnen, 2015) and which allow a "fast and frugal" (Gigerenzer and Brighton, 2009) decision making process.

Starting from this theoretical foundation, our study aims at investigating how entrepreneurs cognitively approach the application of LSAs to develop and validate their entrepreneurial ideas.

We argue that entrepreneurs make sense of LSAs by translating their rather abstract guidelines into a set of heuristics that support each step of the process; and that they make use of business models as 'cognitive lenses' or filters to perform such translation from general guidelines to pragmatic heuristics or simple rules. Thanks to the combination of two generative cycles of sense-making and specification, which gives rise to first-order (i.e. more abstract and generalized) and second-order (i.e. more concrete and specific) heuristics, the resulting simple rules are also 'fast and frugal' - that is, ecologically rational in their ability to exploit environmental information and concretize them into actionable knowledge and inferences. Therefore, the use entrepreneurs make of the BM within a LSAs setting qualifies the BM concept and construct as cognitive lenses to generate fast and frugal heuristics. Moreover, we find that an integrative set of cognitive processes exists which mold and blend together the BM-filtered LSAs heuristics.

These statements have several implications. First, we contribute to strengthen the connection between the business model and the heuristics literature streams and we put forward that the BM can be a generative source of both general first-order and specific second-order heuristics, by providing a relevant empirical case of its use to make sense of a complex process (i.e. LSAs implementation in digital startups) through simple rules; second, we add to the portfolio of existing heuristics by identifying a small set of cognitive shortcuts - all of which generated through the BM construct - that digital entrepreneurs rely on in their early stages of startup development, as they practice the Lean Startup Approaches; third, we investigate how the BM-generated heuristics are learnt, transferred and enacted, and show how their use constitutes a pathway to the adoption of a scientific approach to entrepreneurship (Ghezzi, 2019) for digital startups; fourth, we pave the way for a more explicit inclusion of BM heuristics in the microfoundations discourse in Entrepreneurship and Strategy.

We build this argument by crafting a multiple case study on three digital startups that adopted Lean Startup Approaches in their early stage of development process. Digital startups constitute an important realistic context where to investigate the role of heuristics, outside of laboratorial constraints that typically burdened the psychological studies on individual cognition (Bingham and Eisenhardt, 2011). In our research, digital startups are intended as a vehicle embodying technological development (Güttel et al., 2018); and the multiple case study will enable a fine grained investigation of the role of BMs as heuristics in the context of LSAs, which could later be extended to other technological development endeavors.

Our study is hence organized as follows: after this introduction, a theoretical background is set where the role of BMs as heuristics in extant literature is discussed, together with the part BMs play within LSAs; what follows is a thorough explanation of how the multiple case study was designed and conducted for data gathering and data analysis, so as to generate empirical insights on the issue under scrutiny; then, the 
results of the empirical research are presented and later discussed in the light of the extant theory, and conclusions are drawn on the study's contribution for theory and practice.

\section{Theoretical background}

\subsection{Business Models as heuristics}

The business model (BM), as a concept and construct, is clearly gaining momentum in the academic and practitioner communities (Zott et al., 2011; Massa et al., 2017). Still, its evolution was - and to some extent is - convoluted and controversial. As scientific studies and entrepreneurial or managerial applications involving BMs amassed, so did the alternative ways to define, organize and graphically represent them.

Still, in the last years consensus is converging towards a definition of BMs and an ontological description and representation of its components. The largest share of studies on business model agree that this concept revolves around the notion of "value": the business model is hence intended as a value architecture (Rappa, 2001; Teece, 2010; Foss and Saebi, 2018), an organic system of value-related components, which according to Teece (2010) revolves around three mechanisms: (i) value creation, that is, creating value for the firm's target customers; (ii) value delivery, or transferring value from the firm to the market; and (iii) value capture, implying the firm's ability to reap a share of the value created for customers by enticing them to pay for it.

Although BMs are primarily employed as a strategic tool meant to execute a company's business strategy (Casadesus-Masanell and Ricart, 2010; Teece, 2010), we currently find a common agreement concerning the fact that business models play a paramount role not only in Strategy, but also in the Entrepreneurship field. For instance, business model design is found to significantly impact the performance of entrepreneurial firms, with specific reference to existing tensions between novelty and efficiency BMs (Zott and Amit, 2007); and Demil and colleagues (2015) suggest that BM research can serve to reconnect strategy with entrepreneurship, thus paving the way for the evolution of the Strategic Entrepreneurship domain (Hitt et al., 2001).

Among the alternative research opportunities to extend BM theory and practice, a stream which has seldom caught the eye of academics and practitioners alike - although it could harbor interesting implications - is that of considering business models as heuristics.

Heuristics in firms can be defined as set of "articulated and often informal rules-of-thumb shared by multiple participants within the firm" (Bingham et al. , 2007: 31) which help decision makers to categorize stimuli in problem solving, within contexts characterized by short time available, limited information and novel or unexpected conditions (Newell and Simon, 1972). Heuristics could hence serve as cognitive structures and shortcuts to cope with resource scarcity and uncertainty (Gigerenzer and Brighton, 2009; Goldstein and Gigerenzer, 2009).

Loock and Hinnen (2015: 2027), in their recent review on heuristics in organizations, find that the research on heuristics has been dominated by two alternative perspectives or paradigms: the heuristics-and-biases paradigm and the fast and frugal paradigm. While the first paradigm focuses on heuristics appearing from the individual cognitive ecology of the decision maker, which is inherently bounded and determines biases, the fast and frugal paradigm offers a positive perspective by focusing on heuristics as strategically and 
ecologically rational, as they are accurate in exploiting environmental information, and cognitively efficient in ignoring superfluous information (Gigerenzer and Brighton, 2009). In addition, Bingham and Eisenhardt (2011) argue that heuristics' accuracy is surprising even when compared to more information-intensive and cognitively-burdening approaches, because they exploit individual knowledge about context, they are easy to remember and improve and help constraining the range of opportunities available. In the light of this positive view, Loock and Hinnen (2015) propose that the discussion on heuristics should move from individual heuristics to the role of heuristics in organizations.

An early attempt to connect the two concepts of business models and heuristics is found in Chesbrough and Rosenbloom (2002). The authors argue that "a successful business model creates a heuristic logic that connects technical potential with the realization of economic value"; as a result, "the business model unlocks latent value from a technology" (Chesbrough and Rosenbloom, 2002: 529). This early contribution suggested that the BM acts as an heuristic logic to simplify complex technological potential and transform it into a strategically-relevant performance.

Even though Chesbrough and Rosenbloom (2002) planted a seed for a potentially fruitful theoretical discussion with deep practical implications, their suggestions to look at BMs as heuristics was seldom taken on by other scholars in both BM and heuristics communities; and any time that happened, it was mostly in the form of a rather implicit relationship. Indeed, the stream of business models as heuristics largely escaped the close eye of recent reviews on the BM theory (Zott et al., 2011), where the early work from Chesbrough and Rosenbloom was often mentioned, but no specific discussion on the topic was articulated. The existence of a sort of mutual ignorance separating the two research fields was supported by the findings from Loock and Hinnen's (2015) review, where the authors do not mention any reference to the concept of business model as heuristics in organizations.

However, this BM-heuristics relationship can be inferred in a selection of business model studies.

For instance, Baden-Fuller and Morgan (2010), in their introduction to the seminal Long Range Planning special issue on BMs, make the apparently trivial though significantly insightful proposal to investigate business models as "models"; they argue that models are never identical to what they model, but they constitute a representation that is "simple enough to work through [...], but yet complicated enough to capture sufficient content" (p. 164). Business models are then recipes, which "are used to demonstrate or give advice about how to do something so that the results will come out right" (p. 166); they embody general principles but also particular details; and "they lie between principles - general theory - and templates - exact and exhaustive rules" (p. 166). This discussion promisingly bridges the business model concept with that of fast and frugal heuristics, which also serve to provide fast rules based on general principles.

Another example of a contribution possibly filling the gap between BMs and heuristics is that from Massa and Tucci (2013): in their piece on business model innovation, they go back to Chesbrough and Rosenbloom's (2002) definition and refer to the BM as a mental map, which mediates the way business leverages technology. This reinforces the claim that the BM plays as a cognitive level.

We can also infer an implicitly stated connection between BM and heuristics with reference to the strategic concept of dynamic capability - i.e. "the firm's ability to integrate, build, and reconfigure internal competences to address, or in some cases to bring about, changes in the business environment" (Teece, 2018). Teece (2018) argues that the dynamic capabilities of sensing, seizing and transforming competencies 
are extremely relevant to business model selection and innovation: for instance, startups' business models rarely emerge as consolidated constructs upfront, but need a learning process to achieve validation, as it is proposed in the Lean Startup (Ries, 2011). As a result, business models are enabled by dynamic capabilities, which act on and modify them. In a similar vein, in their work on rational heuristics as simple rules, Bingham and Eisenhardt (2011) find that idiosyncratic dynamic capabilities, such as simplification cycling, act on a new venture's portfolio of heuristics by reshaping them. Therefore, a potential touchpoint between BMs and heuristics emerge as they are both subject to dynamic capabilities' action in the attempt to improve a company's or new venture's performance.

Among the few contributions that explicitly relate business models and heuristics, it is worth mentioning the insightful work from Loock and Hacklin (2015), where the authors explicitly focus on the cognitive foundation for the modelling activity and relate it to the rule-based form giving characterizing Gestalt theory in psychology; they find that business modeling acts as a managerial cognitive process of configuring heuristics.

Massa and colleagues (2017), in their extensive review, make an attempt to organize scattered results on business models as cognitive schema, by referring to contributions like those from Osiyevskyy and Dewald (2015), who investigate BMs in terms of cognitive antecedents; and from Martins and colleagues (2015), who discuss how BMs can be considered as schemas to organize managerial understanding of value creation and exchange mechanisms, which can be innovated through a process of generative cognition. Still, even in their comprehensive review, Massa et al. (2017) mention heuristics only twice, with reference to the studies from Chesbrough and Rosenbloom (2002) and Loock and Hacklin (2015).

More recently, this research stream seemed to gain a certain momentum with the appearance of works that explicitly address the cognitive dimension of business models: for instance, Frankenberger and Sauer (2019) investigated managerial attention focus and intensity as cognitive antecedents of business model design, thus shifting from an external to an internal view of business model change triggers; and Roessler et al. (2019) analyzed the cognitive biases in business model design of Corporate entrepreneurship initiatives.

Table 1 - References to the relationship between business models and heuristics

\begin{tabular}{|l|l|}
\hline \multicolumn{1}{|c|}{ Source } & \multicolumn{1}{|c|}{ Business model-heuristics relationship } \\
\hline Chesbrough and Rosenbloom (2002) & $\begin{array}{l}\text { Business model creating a heuristic logic that connects technical potential } \\
\text { with the realization of economic value }\end{array}$ \\
\hline Baden-Fuller and Morgan (2010) & $\begin{array}{l}\text { Business models as models, recipes that lie between principles - general } \\
\text { theory - and templates - exact and exhaustive rules }\end{array}$ \\
\hline Massa and Tucci (2013) & Business model as mental map \\
\hline $\begin{array}{l}\text { Teece (2018); Bingham and Eisenhardt } \\
\text { (2011) }\end{array}$ & $\begin{array}{l}\text { Business models and heuristics enabled and transformed by dynamic } \\
\text { capabilities }\end{array}$ \\
\hline Loock and Hacklin (2015) & $\begin{array}{l}\text { Business model acting as a managerial cognitive process of configuring } \\
\text { heuristics under the Gestalt theory in psychology }\end{array}$ \\
\hline Osiyevskyy and Dewald (2015) & $\begin{array}{l}\text { Business models investigated in terms of cognitive antecedents } \\
\text { Martins and colleagues (2015) }\end{array}$ \\
$\begin{array}{l}\text { Business models as schemas to organize managerial understanding of } \\
\text { value creation and exchange mechanisms, innovated through a process of } \\
\text { generative cognition }\end{array}$ \\
\hline Massa and colleagues (2017) & $\begin{array}{l}\text { Business model as cognitive schema } \\
\text { focus and intensity) }\end{array}$ \\
\hline Frankenberger and Sauer (2019) & $\begin{array}{l}\text { Business models analyzed in terms of cognitive biases to antagonize } \\
\text { through cognitive mechanisms and processes }\end{array}$ \\
\hline Roessler et al. (2019)
\end{tabular}


This survey of extant literature, summarized in Table 1, allows to argue that business model theory has been seldom investigated in relation with the concept of heuristics, although a number of implicit connections (e.g. Baden-Fuller and Morgan, 2010; Massa and Tucci, 2011; Teece, 2018; Bingham and Eisenhardt, 2011) and fewer explicit relationships (e.g. Chesbrough and Rosenbloom, 2002; Loock and Hacklin, 2015; Roessler et al., 2018; Frankenberger and Sauer, 2019) pave the way for a promising research avenue.

\subsection{Business Models in Lean Startup Approaches}

Among the many practices the entrepreneurial community took up to support and enable startups' development, a recent and noteworthy case is represented by Customer Development (Blank, 2007) and the Lean Startup (Ries, 2011).

Elaborated by Steve Blank, Customer Development emerged as a criticism to the "fallacy of the perfect business plan" (Blank, 2007; 2013; Blank and Dorf, 2012), which often ends up being a convoluted document expressing a causation logic that applied to a risky rather than an uncertain environment (Sarasvathy, 2001); according to Blank, instead of writing a business plan, startups had to iteratively and tentatively try to make experiments and tests their assumptions in the market, so as to gather customer feedback and trigger a process called validated learning, where feedback would be used to confirm or "pivot" the original business idea. This way, startups were "discovering" (i.e. identifying prospects of "earlyvangelists" to obtain feedback from and later "developing" would-be customers (i.e. run experiments involving them, and change the startup's business idea according to the test results), rather than products and services. Notwithstanding this business plan vs Customer Development dichotomy, a recent study shows that entrepreneurs mended the conflict by making experimenting the antecedent of business planning, and feeding the business plan with data stemming from customer discovery (Ghezzi, 2019).

The Lean Startup (Ries, 2011) reinforces the Customer Development philosophy for startup development by combining it with Lean Manufacturing's one, thus dictating that startups are to eliminate waste, constituted by all of the activities customers do not want or ask for: waste reduction hence enables a lean experimental evolution and learning process for the startup, that is compatible with its limited resources available.

Because of their evident similarities in scope and aim, Customer Development and Lean Startup have been combined and aggregated under the label of Lean Startup Approaches (LSAs) (Ghezzi and Cavallo, 2020).

While LSAs experienced significant success in many entrepreneurial ecosystems, being largely adopted by entrepreneurs (Frederiksen and Brem, 2017; Ghezzi, 2019; Yang et al., 2019), they were seldom backed by strong theoretical grounding. As a result, they are currently attracting significant research effort with the purpose to frame them theoretically and at the same time advance their practical implications.

A recent review from Bortolini and colleagues (2018) found that LSAs are rooted in the Learning School in Strategy - a finding shared by Contigiani and Levinthal (2019); at the same time, LSAs represent a pragmatic embodiment of an the entrepreneurial effectuation and bricolage logic (Sarasvathy, 2001; Fisher, 2012; Baker and Nelson, 2005; Frederiksen and Brem, 2017; Silva et al., 2019). 
LSAs also show a connection with the business model concept. In fact, both Customer Development and Lean Startup suggest the use of the startup's BM to respectively enable customer discovery, and provide the basis for the formulation of assumptions and hypotheses on the startup's viability. Later versions of the Lean Startup Approaches (Blank, 2013) suggest the use of a specific BM construct, the business model canvas (Osterwalder and Pigneur, 2010); however, this suggestion should not be seen as limiting the BM's applicability within LSAs domain, since the BM canvas and its parameters lead back to the value creation, delivery and capture logics (Teece, 2010) that broadly describe the BM as a value architecture.

Hence, LSAs indicate to leverage the business model concept: still, they explicitly do so only with reference to the local phases of discovery and hypotheses formulation. As a result, they tend overlook or take for granted how the business model is cognitively used by entrepreneurs throughout the LSAs process.

Moreover, while LSAs are broadly praised for helping entrepreneurs in turning their original ideas into viable new ventures, recent studies (e.g. Ghezzi, 2019) suggest that entrepreneurs embarking in LSAs' application may experience a number of pragmatic problems constraining their effectiveness.

\section{Research Methods}

This study is designed as a multiple case study (Yin, 1984; Eisenhardt, 1989; Eisenhardt and Graebner, 2007), whereas a case study is an "empirical inquiry that investigates a contemporary phenomenon within its real-life context; when the boundaries between phenomenon and context are not clearly evident; and in which multiple sources of evidence are used" (Yin, 1984: 23).

The multiple case study investigates the phenomenon of how three digital startups cognitively approached the application of the Lean Startup Approaches in their early stages of development in order to validate their business idea, and how they used the business model in this context. In line with Clark and colleagues (2010), we selected an interpretive research approach that "gives voice in the interpretation of events in a first-order analysis to the people actually experiencing those events" (Clark et al., 2010: 403). We then formulated a second order interpretation of the informants' voices which referred to - but was not limited to - Business Model theory and Heuristics literature, possibly contributing to theory building.

When asking informants to recollect how they applied the LSAs and used BMs within such framework, no explicit mention was made of the notions of heuristics and simple rules, and informants were not exposed to any relationship between BMs and heuristics; this follows the guidelines proposed in Eisenhardt (1989), according to which the researchers involved in theory building shall make evidences surface from the empirical research rather than drive informants' conclusions.

Concerning case sampling, the three digital startups were selected from an original database created by the authors, which listed all digital startups launched in Italy since $2012^{1}$. These three startups, named Startup $X$, Startup $Y$ and Startup $Z$, were involved in the study as they declared in an earlier interaction with the researchers that they recently applied Lean Startup Approaches and successfully reached product-market fit: this allowed to assume the phenomenon under scrutiny - i.e. the use of the business model within LSAs context - could be recalled and observed (Meredith, 1998; Eisenhardt, 1989). These digital startups had digital technologies at the core of their business, and could hence be considered an embodiment and

${ }^{1}$ Further information concerning the original database are omitted in this version of the manuscript to ensure anonymity, and are available upon request. 
vehicle of technological development. For all the three cases, the embedded unit of analysis was represented by the process of enacting LSAs and the possible role of the BM construct in each of its steps. Descriptive information about the digital startups involved are reported in Table 2.

Table 2 - Descriptive information on digital startups included in the multiple case study

\begin{tabular}{|c|c|c|c|c|}
\hline $\begin{array}{l}\text { Startup } \\
\text { (real name } \\
\text { omitted to } \\
\text { ensure } \\
\text { anonymity) }\end{array}$ & Founded & Industry & $\begin{array}{l}\text { Description of the business } \\
\text { idea }\end{array}$ & $\begin{array}{c}\text { Informants interviewed } \\
\text { (number of interviews } \\
\text { per informant) }\end{array}$ \\
\hline Startup X & 2018 & Food eCommerce & $\begin{array}{l}\text { Digital platform connecting } \\
\text { fishermen, end users and other } \\
\text { third parties to deliver clean fish } \\
\text { in fancy packaging straight to the } \\
\text { customers' door }\end{array}$ & $\begin{array}{l}\text { CEO (1), CMO (1), COO (1), } \\
\text { Product Specialist (1) }\end{array}$ \\
\hline Startup Y & 2017 & Fintech & $\begin{array}{l}\text { Digital application that creates } \\
\text { an electronic wallet collecting } \\
\text { spare money from each } \\
\text { customer's purchases by } \\
\text { rounding up the actual expense. } \\
\text { The app allows customers to } \\
\text { keep track of expenses and } \\
\text { reinvest their savings }\end{array}$ & $\begin{array}{l}\text { CEO (1), COO (2), CDO (1), } \\
\text { CFO (1) }\end{array}$ \\
\hline Startup Z & 2016 & $\begin{array}{l}\text { Marketing } \\
\text { services }\end{array}$ & $\begin{array}{l}\text { Digital platform enabling } \\
\text { "mystery shopping" by } \\
\text { connecting brands needing to } \\
\text { gather specific product/service- } \\
\text { related information (e.g. quality } \\
\text { of service, compliance, in-store } \\
\text { location) and end users willing to } \\
\text { act as secret shoppers and } \\
\text { provide detailed reports on their } \\
\text { performed tasks }\end{array}$ & $\begin{array}{l}\text { CEO (1), CMO (1), Project } \\
\text { Manager (1), Product } \\
\text { Specialist (1) }\end{array}$ \\
\hline
\end{tabular}

The research was designed as a multiple case study to potentially generalize results, while enabling a comparative analysis of the findings (Meredith, 1998), whereas the three digital startups involved are characterized by fairly different business ideas and cover heterogeneous markets - namely Food eCommerce, Fintech and Marketing Services. Still, limiting the number of cases included in the sample allowed to acquire an extensive qualitative description of the process investigated that could hardly be obtained from a much wider sample (Handfield and Melnyk, 1998).

\subsection{Data gathering}

Following the tenets of case study research, well exposed in Yin (1984), our data and information were collected through multiple sources of evidence.

We leveraged face-to-face interviews as the primary source of information; these interviews were semistructured, as they started from some key issues related to the broader research question but allowed other issues to emerge from the open discussion with informants (Walsham, 1995). The interview protocol was validated through three pilot interviews with digital entrepreneurs others than those interviewed later within the multiple case study, whose contacts appeared in the original database: this step allowed to 
validate the clarity and insightfulness of the questions asked, although minor wording changes to the original versions of some questions were introduces thanks to the testers' feedback.

The validated protocol guided the twelve interviews with twelve informants belonging to the three digital startups in the sample. Four informants were involved for each startup. Interviews to Startup $X$ took place between February and May 2018, and involved all of the three founders - respectively taking on the roles of the current Chief Executive Officer (CEO), Chief Operations Officer (COO) and Chief Marketing Officer (CMO) - and a Product Specialist. Interviews to Startup Y took place between November 2017 and April 2018, involving all the four startup founders - with the current roles of CEO, COO, Chief Digital Officer (CDO) and Chief Financial Officer (CFO); in this case, the second interview involved both the $\mathrm{COO}$ and the $\mathrm{CDO}$ at the same time, and the COO was interviewed by herself a second time. Interviews to Startup Z took place between June and December 2017, and the informants were two founders - with the roles of CEO and $\mathrm{CMO}-$, one Project Manager and one Product Specialist. All informants were selected as they declared they played an active role in applying LSAs within their digital startups.

The interviews lasted between 54 to 95 minutes each, with an average of 78 minutes.

The interviews protocol was designed to shed light on the study's research question, and revolved around the use of the business model within the context of Lean Startup Approaches by informants and their startups. In the first part of the interview, informants were first asked to recall which were the main steps of the LSAs they applied, so as to control for their familiarity with the approaches and related tools (with questions like: "What was the first step when applying Lean Startup Approaches within your startup? What was the goal of such step? Which were the main concepts and tools you leveraged within that step? What was the overall evaluation of your and your team's experience in using the LSAs?").

As a second part of the interview, informants were asked to recall if, when, how and why they used the concept and construct of the business model within each step of the LSAs they reconstructed in the first part; and what BM construct/s they used, so as to check for a common understanding of the BM definition. Questions aimed at investigating not just technicalities, but even cognitive mechanisms, peculiarities and idiosyncrasies related to the use of the $\mathrm{BM}$; therefore, the interviewers encouraged respondents to specifically reflect on the how and why the BM was used - or not used - at a given step, and which were the expected or unexpected outcomes of the use of this construct. The main questions put at this stage were: "With reference to this specific LSAs step you reconstructed, did you use and apply the business model construct? What kind of BM concept and construct did you use at this step? Can you recall why you used it, consistently with the goal of this LSAs step? And how exactly you used it? What were the outcomes of using the BM in this step? What were the advantages and disadvantages? Did the use of the BM help you and your team reasoning in a certain way when tackling the step-specific problems?".

The relatively recent application of the LSAs by all three digital startups - Startup X founders declared they relied on LSAs in early 2018, while Startup Y and Startup Z applied it in mid-2017 and late 2016, respectively - made for an easier recollection, to mitigate any retrospective bias; this choice of sampling helped tackling observer bias (Yin, 1984), which was also limited by the inclusion of a plurality of voices from the very same startup recollecting the LSAs application process.

To enhance our multiple case study's validity and reliability, the accuracy of the information provided by the respondents where triangulated with multiple sources of information (Eisenhardt, 1989; Yin, 1984), including those reported in Table 4. 
Table 4 - Summary of sources of information for the digital startups included in the multiple case study

\begin{tabular}{|l|c|c|c|}
\hline Source of information & Startup X & Startup Y & Startup Z \\
\hline Interviews & 4 & $\begin{array}{c}4 \text { (of which, 1 involving } \\
\text { both COO and CDO) }\end{array}$ & 4 \\
\hline Different BM sketches & 5 & 4 & 1 \\
\hline Business Plan versions & 2 & 1 & 12 \\
\hline $\begin{array}{l}\text { Informal e-mails and } \\
\text { communications }\end{array}$ & 22 & 9 pages & 15 pages \\
\hline $\begin{array}{l}\text { Other notes and drafts } \\
\text { referring to LSAs } \\
\text { applications }\end{array}$ & 5 pages & 6 pages & 3 \\
\hline $\begin{array}{l}\text { Internet pages } \\
\text { Newspaper and magazine } \\
\text { articles }\end{array}$ & 3 pages & 3 & 31 pages \\
\hline
\end{tabular}

These additional sources of archival data and information and external documents were combined to the informative content contained in the semi-structured interviews through an iterative process, where the researchers strived to collect as much secondary sources as possible before the interviews (as recommended in Yin, 1984), but were open to receive additional sources of information the informants cited during the interview or delivered right after it. This approach possibly strengthened data triangulation (Siggelkow, 2007).

\subsection{Data analysis}

Data analysis relied on a full transcription and record of responses from the interviews; informants were also contacted by telephone or e-mail after their interviews to provide clarifications on any missing or unclear data.

A within-case and a cross-case data analyses were hence performed, in order to generate insight on the single digital startup with reference to the study's research question, and enable a comparison between the different cases involved in the research design (Eisenhardt, 1989)

Within-case interview content analysis leveraged the 'open coding' practice from Grounded Theory methodology (Glaser and Strauss, 1967; Strauss and Corbin, 1998), a method suitable to study complex phenomena through a clearly defined procedure based on coding - i.e. labels, concepts and words used to produce theory from interviews, rather than the mere finding of facts (Glaser and Strauss, 1967). The empirical material was codified through textual analysis, and a software was used for archiving purposes.

For each of the three cases, we built an inductive coding starting from informants' quotes, and based on both "in vivo" codes - i.e. a code reporting the exact wording used by the informants to describe the application of LSAs and the use of the BM in it - and constructed codes - i.e. constructed wording induced by the researchers - (Glaser and Strauss, 1967). These codes were hence iteratively contrasted and compared in order to group them into tentative constructs from individual cases at a higher level of 
abstraction (Eisenhardt and Graebner, 2007), which could allow to capture the most important constituent elements of how entrepreneurs cognitively approach LSAs and make use of the BM within this context.

Through the inductive coding, fine-grained in vivo codes were transformed into aggregated concepts, and the real-world content obtained from the qualitative interviews enabled us to proceed with the abstraction and theory building (Saldana, 2009).

Within cross-case analysis, the tentative constructs developed from the individual cases of Startups $X, Y$ and $Z$ were compared, so as to clarify the constructs on strengthen the logical arguments concerning the cognitive approach behind LSAs and the use of the BM (Eisenhardt and Graebner, 2007). This concluding phase of cycling between emergent theory and data allows to extract possibly novel findings and insights from a multiple case study, thus making for theory building (Eisenhardt, 1989).

All the case results were finally reviewed and confirmed by the informants, to further limit any observer bias in the attempt to provide a robust interpretation of the qualitative and complex phenomenon under scrutiny (Yin, 1984).

The multiple case study's findings coded according to the research method revealed valuable insights on how the digital startups cognitively approached the Lean Startup Approaches and made use of the business model concept and construct in such setting.

These findings are framed and organized according to the LSAs steps the startups followed, consistently with the interviews' protocol and the interviews' coding. In fact, all the three startups' informants agreed upon the main steps LSAs are made of, which, consistently with the literature (Ries, 2011; Blank and Dorf, 2012; Eisenmann et al., 2012; Blank, 2013), are listed and briefly defined as follows:

1. Set a vision and translate it into 'falsifiable hypotheses' - that is, identify an original business idea and define a set of assumptions or hypotheses your business idea is built on, and which should be tested (Table 5);

2. Specify Minimum Viable Products (MVPs) and MVP-related experiments and tests - that is, craft one or more MVPs that should resemble your business idea in a feasible but cost-effective way, and define how your MVPs could enable an experimenting and testing process to falsify your hypotheses (Table 6);

3. Prioritize experiments and tests - that is, define which tests have the most significant impact on the business idea's feasibility and hold the highest share of risk (Table 7);

4. Run experiments and tests and trigger a learning process to select one option among persevering, pivoting or perishing - that is, iteratively enact the experiments and tests based on the MVPs, gather data from customers interactions with the MVP in the setting provided by the test, and analyze the feedback on your business idea to understand whether you should (i) persevere with your idea as you achieved product-market fit, (ii) modify or pivot your idea based on partly divergent customer feedback; or (iii) let your idea perish based on market rejection (Table 8).

Table 5 - Results on opportunity sense-making and falsifiable hypotheses formulation

\begin{tabular}{|c|l|l|l|}
\hline Representative quotes & \multicolumn{1}{|c|}{ Codes } & Heuristics (simple rules) & Use of the BM \\
\hline $\begin{array}{l}\text { "From the very beginning, as I } \\
\text { strived to get my idea down to }\end{array}$ & $\begin{array}{l}\text { In-vivo: } \\
\bullet \quad \text { e.g. "idea down to }\end{array}$ & $\begin{array}{l}\text { Assess new } \\
\text { opportunities and }\end{array}$ & $\begin{array}{l}\text { Opportunity sense- } \\
\text { making }\end{array}$ \\
\hline
\end{tabular}




\begin{tabular}{|c|c|c|c|}
\hline $\begin{array}{l}\text { earth, I almost automatically } \\
\text { started reasoning in terms of } \\
\text { value. I kept asking myself: 'Ok, } \\
\text { but what's the value for } \\
\text { companies getting my services? } \\
\text { What's the value for shoppers? } \\
\text { And what's the value for me?' I } \\
\text { was basically trying to build a } \\
\text { first sketch of a business model in } \\
\text { my mind" (CEO - Startup Z) }\end{array}$ & $\begin{array}{l}\text { earth"; "value" (value } \\
\text { for companies, value } \\
\text { for shoppers, value } \\
\text { for me); "first sketch } \\
\text { of a business model in } \\
\text { my mind" } \\
\text { Constructed: } \\
\text { - Opportunity assessed } \\
\text { and business idea } \\
\text { formed in terms of } \\
\text { 'value' } \\
\text { Sketching the idea } \\
\text { around a business } \\
\text { model } \\
\text { Better perceiving and } \\
\text { making sense of } \\
\text { opportunities }\end{array}$ & $\begin{array}{l}\text { related business ideas } \\
\text { formed in terms of } \\
\text { value } \\
\text { Use the business model } \\
\text { as a cognitive map to } \\
\text { frame opportunities } \\
\text { around value creation, } \\
\text { value delivery and value } \\
\text { capture upfront } \\
\text { Look at reality from a } \\
\text { business model angle, } \\
\text { to see if internal } \\
\text { resources and external } \\
\text { phenomena combine to } \\
\text { form a business model }\end{array}$ & \\
\hline $\begin{array}{l}\text { "LSAs require you to clearly state } \\
\text { the assumptions backing your } \\
\text { business idea. As Steve Blank } \\
\text { suggests, we did that through the } \\
\text { business model construct. So, our } \\
\text { overarching assumption that } \\
\text { sounded like 'customers will buy } \\
\text { fish that is delivered to your } \\
\text { home straight from the } \\
\text { fisherman's boat', and was quite } \\
\text { generic, was translated into } \\
\text { specific hypotheses like 'we } \\
\text { assume fish shall be clean', 'we } \\
\text { assume customers will pay a } \\
\text { premium price for this online } \\
\text { service', 'we assume our } \\
\text { packaging must be fancy', and so } \\
\text { on" (COO - Startup X). }\end{array}$ & $\begin{array}{l}\text { In vivo: } \\
\text { - e.g. "state the } \\
\text { assumptions [...] } \\
\text { through the business } \\
\text { model construct"; } \\
\text { "overarching } \\
\text { assumption"; "specific } \\
\text { hypotheses". } \\
\text { Constructed: } \\
\text { - Passing from generic } \\
\text { and fuzzy to specific } \\
\text { and testable } \\
\text { assumptions } \\
\text { Value and customer } \\
\text { centricity }\end{array}$ & $\begin{array}{l}\text { - Formulate hypotheses } \\
\text { and assumptions that } \\
\text { are falsifiable and } \\
\text { testable and revolve } \\
\text { around the concept of } \\
\text { value } \\
\text { - Use the business model } \\
\text { to pass from generic } \\
\text { opportunities to specific } \\
\text { and testable } \\
\text { assumptions } \\
\text { Consider the business } \\
\text { model parameters as a } \\
\text { pool of elements to } \\
\text { make hypotheses and } \\
\text { assumptions on the }\end{array}$ & Hypothesizing \\
\hline $\begin{array}{l}\text { "The BM helped us in better } \\
\text { perceiving and giving form to } \\
\text { opportunities around a set of } \\
\text { hypotheses. And isn't the } \\
\text { business model a comprehensive } \\
\text { and almost ready-to-go set of } \\
\text { hypotheses you make about your } \\
\text { startup? When you as an } \\
\text { entrepreneur say 'my startup will } \\
\text { sell this product, to that market, } \\
\text { through those channels and with } \\
\text { these ways to engage } \\
\text { customers', so you are describing } \\
\text { your business model, aren't you } \\
\text { actually implying that you } \\
\text { assume your startup can do all } \\
\text { of those things that way, and } \\
\text { these BM assumptions need } \\
\text { falsification in the real world?" } \\
\text { (CEO-Startup Z) }\end{array}$ & $\begin{array}{l}\text { In vivo: } \\
\text { - e.g. "opportunities"; } \\
\text { "hypotheses"; } \\
\text { "falsification" } \\
\text { Constructed: } \\
\text { - Business model as } \\
\text { comprehensive and } \\
\text { almost ready-to-go } \\
\text { set of hypothesis } \\
\text { about the startup } \\
\text { Value and customer } \\
\text { centricity }\end{array}$ & $\begin{array}{l}\text { multidimensional } \\
\text { concept of value, in } \\
\text { terms of: (i) value } \\
\text { creation, (ii) value } \\
\text { delivery, (iii) value } \\
\text { capture } \\
\text { - Always place the } \\
\text { customer at the center } \\
\text { of your hypotheses and } \\
\text { startup equation }\end{array}$ & \\
\hline
\end{tabular}




\begin{tabular}{|c|c|c|c|}
\hline $\begin{array}{l}\text { "The business model helped me } \\
\text { not being up in the air as I used } \\
\text { to be. At that time I didn't have } \\
\text { much information and data to } \\
\text { rely on, but at least the business } \\
\text { model was somewhat telling me } \\
\text { where to look at and focus on. } \\
\text { Any time I gathered new } \\
\text { information, data and knowledge } \\
\text { from the outside, or any time one } \\
\text { guy in the team had a new idea, } \\
\text { we tried to fit it into the BM } \\
\text { components we designed before, } \\
\text { and strived to make sense of it. } \\
\text { [...] we were always looking for } \\
\text { consistency between the } \\
\text { environment, our business model } \\
\text { and its internal components; this } \\
\text { way we kept track of our early } \\
\text { messy development, and } \\
\text { tentatively knew what to go for } \\
\text { and what to discard" (CDO - } \\
\text { Startup Y) }\end{array}$ & $\begin{array}{l}\text { In vivo: } \\
\text { - e.g. "focus"; } \\
\text { "information and } \\
\text { data"; "new } \\
\text { information, data and } \\
\text { knowledge"; } \\
\text { "outside"; "new idea"; } \\
\text { "consistency" } \\
\text { Constructed: } \\
\text { - } \quad \text { Not being up in the air } \\
\text { - Focus attention and } \\
\text { effort } \\
\text { - Fitting information } \\
\text { coming from the } \\
\text { outer world and new } \\
\text { team ideas into the } \\
\text { business model } \\
\text { components } \\
\text { Searching for } \\
\text { consistency between } \\
\text { environment, } \\
\text { business model and } \\
\text { its internal } \\
\text { components } \\
\text { Selecting what to go } \\
\text { for and what to } \\
\text { discard }\end{array}$ & 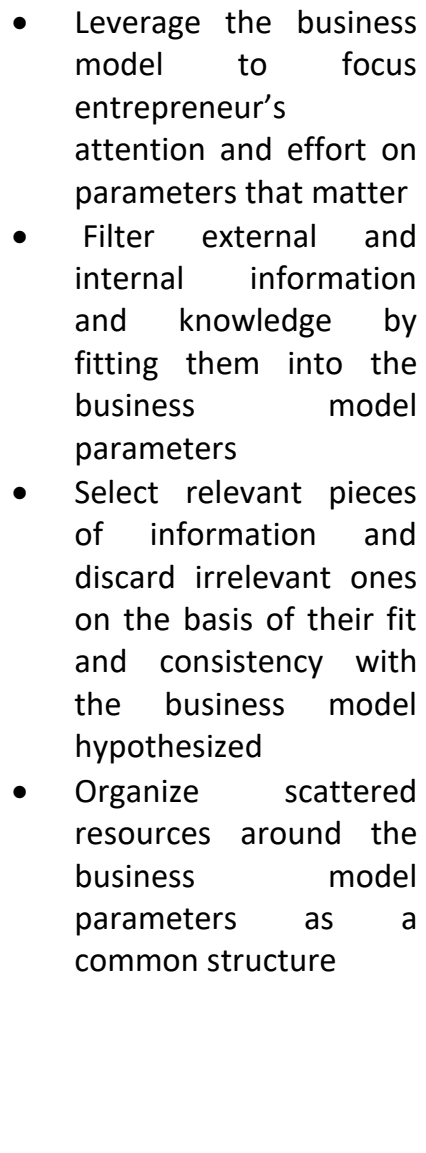 & $\begin{array}{l}\text { Filtering, selecting } \\
\text { and organizing } \\
\text { information and } \\
\text { knowledge }\end{array}$ \\
\hline
\end{tabular}

Table 6 - Results on experimenting and testing design

\begin{tabular}{|c|c|c|c|}
\hline Representative quotes & Codes & Heuristics (simple rules) & Use of the BM \\
\hline $\begin{array}{l}\text { "This is a key step in the process. } \\
\text { It is how you concretize all of } \\
\text { your philosophical assumptions } \\
\text { and make them testable" (COO - } \\
\text { Startup X) }\end{array}$ & $\begin{array}{l}\text { In vivo: } \\
\text { - e.g. "key step"; } \\
\text { "concretize"; } \\
\text { "philosophical } \\
\text { assumptions"; } \\
\text { "testable" } \\
\text { Constructed: } \\
\text { - Concretizing } \\
\text { philosophical } \\
\text { assumptions into } \\
\text { actionable tests }\end{array}$ & \multirow{3}{*}{$\begin{array}{l}\text { Design experiments } \\
\text { that take into fair } \\
\text { account the } \\
\text { multidimensional } \\
\text { nature of value in its } \\
\text { creation, delivery and } \\
\text { capture components } \\
\text { Avoid the common bias } \\
\text { to design experiments } \\
\text { testing the value } \\
\text { proposition (i.e. } \\
\text { products, services and } \\
\text { solutions) only } \\
\text { Concretize } \\
\text { philosophical } \\
\text { hypotheses and } \\
\text { assumptions into } \\
\text { actionable tests by } \\
\text { using the business } \\
\text { model as a connection } \\
\text { and common structure } \\
\text { Start from a Minimum } \\
\text { Viable Business Model } \\
\text { to design Minimum }\end{array}$} & \multirow[t]{3}{*}{$\begin{array}{l}\text { Designing } \\
\text { multidimensional } \\
\text { experiments and } \\
\text { tests }\end{array}$} \\
\hline $\begin{array}{l}\text { "This is the part of the game } \\
\text { when you try to make LSAs } \\
\text { actionable and measurable" (CFO } \\
\text { - Startup Y) }\end{array}$ & $\begin{array}{l}\text { In vivo: } \\
\text { - e.g. "actionable"; } \\
\text { "measurable" } \\
\text { Constructed: } \\
\text { - } \quad \text { Actionable and } \\
\text { measurable } \\
\text { experiments }\end{array}$ & & \\
\hline $\begin{array}{l}\text { "[I] picked up [the MVP] as an } \\
\text { artifact to obtain the largest } \\
\text { share of customer information } \\
\text { with the smallest upfront } \\
\text { investment. Considering at that } \\
\text { time we were almost broke and }\end{array}$ & $\begin{array}{l}\text { In vivo: } \\
\text { - e.g. "MVP"; } \\
\text { "customer } \\
\text { information"; } \\
\text { "upfront investment"; } \\
\text { "bootstrapping" }\end{array}$ & & \\
\hline
\end{tabular}




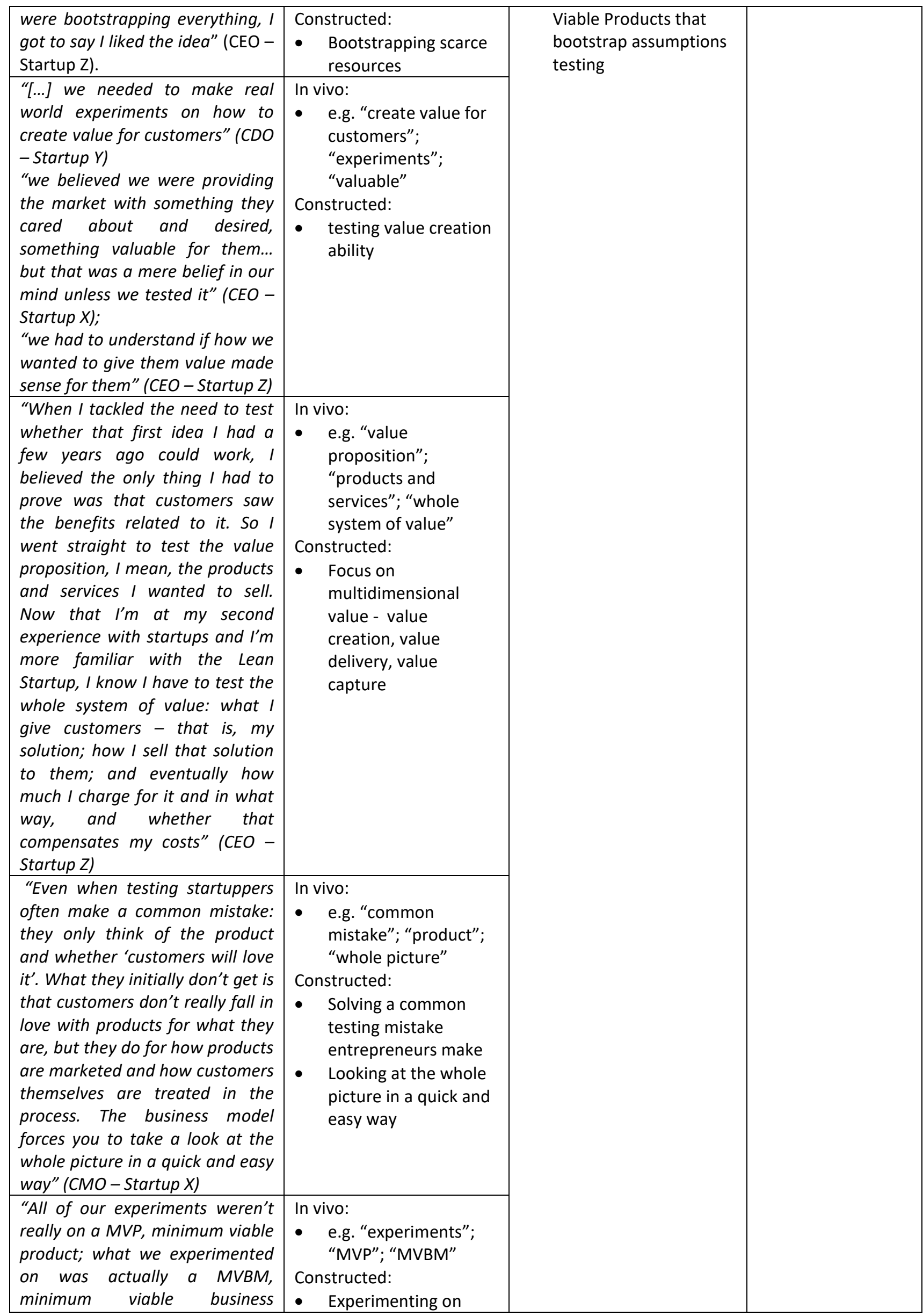




\begin{tabular}{|l|l|l|l|}
\hline model!" (CDO-Startup Y) & $\begin{array}{l}\text { Minimum Viable } \\
\text { Business Model }\end{array}$ & & \\
\hline
\end{tabular}

Table 7-Results on prioritizing tests

\begin{tabular}{|c|c|c|c|}
\hline Representative quotes & Codes & Heuristics (simple rules) & Use of the BM \\
\hline $\begin{array}{l}\text { "Understanding which tests to } \\
\text { run first - or to run at all-was a } \\
\text { matter of evaluating risk and } \\
\text { uncertainty. Those assumptions } \\
\text { we made about our startup that } \\
\text { were riskier had to be prioritized, } \\
\text { in line with the RAT [Riskier } \\
\text { Assumption Testing] approach in } \\
\text { LSAs. The uncertain ones, which } \\
\text { means those we knew little } \\
\text { about, had to be tested first. [...] } \\
\text { In this process, we performed risk } \\
\text { evaluation by benchmarking our } \\
\text { hypothesized business model } \\
\text { elements with existing business } \\
\text { models from other companies } \\
\text { that were up and running: if we } \\
\text { found some of our hypotheses } \\
\text { were already met in extant } \\
\text { business models, we assumed } \\
\text { they were less risky than } \\
\text { hypotheses we could not find } \\
\text { anywhere else" (COO-Startup X) }\end{array}$ & $\begin{array}{l}\text { In vivo: } \\
\text { - e.g. "risk"; } \\
\text { "uncertainty"; } \\
\text { "prioritize"; “RAT" } \\
\text { Constructed: } \\
\text { - } \quad \text { Selecting risky and } \\
\text { uncertain } \\
\text { assumptions to test } \\
\text { first based on } \\
\text { assumptions validated } \\
\text { in other companies' } \\
\text { business models }\end{array}$ & \multirow[t]{2}{*}{$\begin{array}{l}\text { - Contrast and compare } \\
\text { your business model's } \\
\text { assumptions with other } \\
\text { existing companies' or } \\
\text { startups' business } \\
\text { model } \\
\text { - Select and prioritize } \\
\text { assumptions that have } \\
\text { not been tested and } \\
\text { validated by existing } \\
\text { companies' or startups' } \\
\text { business models, since } \\
\text { these assumptions are } \\
\text { the riskiest } \\
\text { Assign a lower priority } \\
\text { to assumption already } \\
\text { validated in existing } \\
\text { business models } \\
\text { Do not assign any } \\
\text { priority a priori to value } \\
\text { proposition tests }\end{array}$} & \multirow[t]{2}{*}{$\begin{array}{l}\text { Prioritizing through } \\
\text { analogical } \\
\text { arguments }\end{array}$} \\
\hline $\begin{array}{l}\text { "This real-world example shows } \\
\text { how you prioritize tests: you see } \\
\text { what's been validated by other } \\
\text { startups' business models in the } \\
\text { market, and you focus your } \\
\text { experiments on what's uncertain } \\
\text { as it found no validation yet" }\end{array}$ & $\begin{array}{l}\text { In vivo: } \\
\text { - e.g. "prioritize tests"; } \\
\text { "other startups' } \\
\text { business models"; } \\
\text { "uncertain"; “no } \\
\text { validation" } \\
\text { Constructed: } \\
\text { - } \quad \text { Priorities emerging } \\
\text { from identifying } \\
\text { analogies between } \\
\text { startup's business } \\
\text { model and existing } \\
\text { business models }\end{array}$ & & \\
\hline
\end{tabular}

Table 8 - Results on running tests to trigger validated learning

\begin{tabular}{|c|c|c|c|}
\hline Representative quotes & Codes & Heuristics (simple rules) & Use of the BM \\
\hline $\begin{array}{l}\text { "As an engineer, I was looking for } \\
\text { robust experiment design leading } \\
\text { to possibly optimal solutions. The } \\
\text { Lean Startup and Customer } \\
\text { Development, coupled with an } \\
\text { evident shortage in resources like } \\
\text { time, money, information and } \\
\text { people, made me look at the }\end{array}$ & $\begin{array}{l}\text { In vivo: } \\
\text { - } \quad \text { e.g. "robust } \\
\text { experiments"; } \\
\text { "optimal solutions"; } \\
\text { "good enough" } \\
\text { Constructed: } \\
\text { - } \quad \text { Tests leading to } \\
\text { satisfactory results }\end{array}$ & $\begin{array}{l}\text { - Process all test results } \\
\text { from customer } \\
\text { discovery through the } \\
\text { lenses of the business } \\
\text { model } \\
\text { - Iteratively contrast and } \\
\text { compare the tests } \\
\text { results with the original }\end{array}$ & $\begin{array}{l}\text { Learning processing } \\
\text { and concretizing }\end{array}$ \\
\hline
\end{tabular}




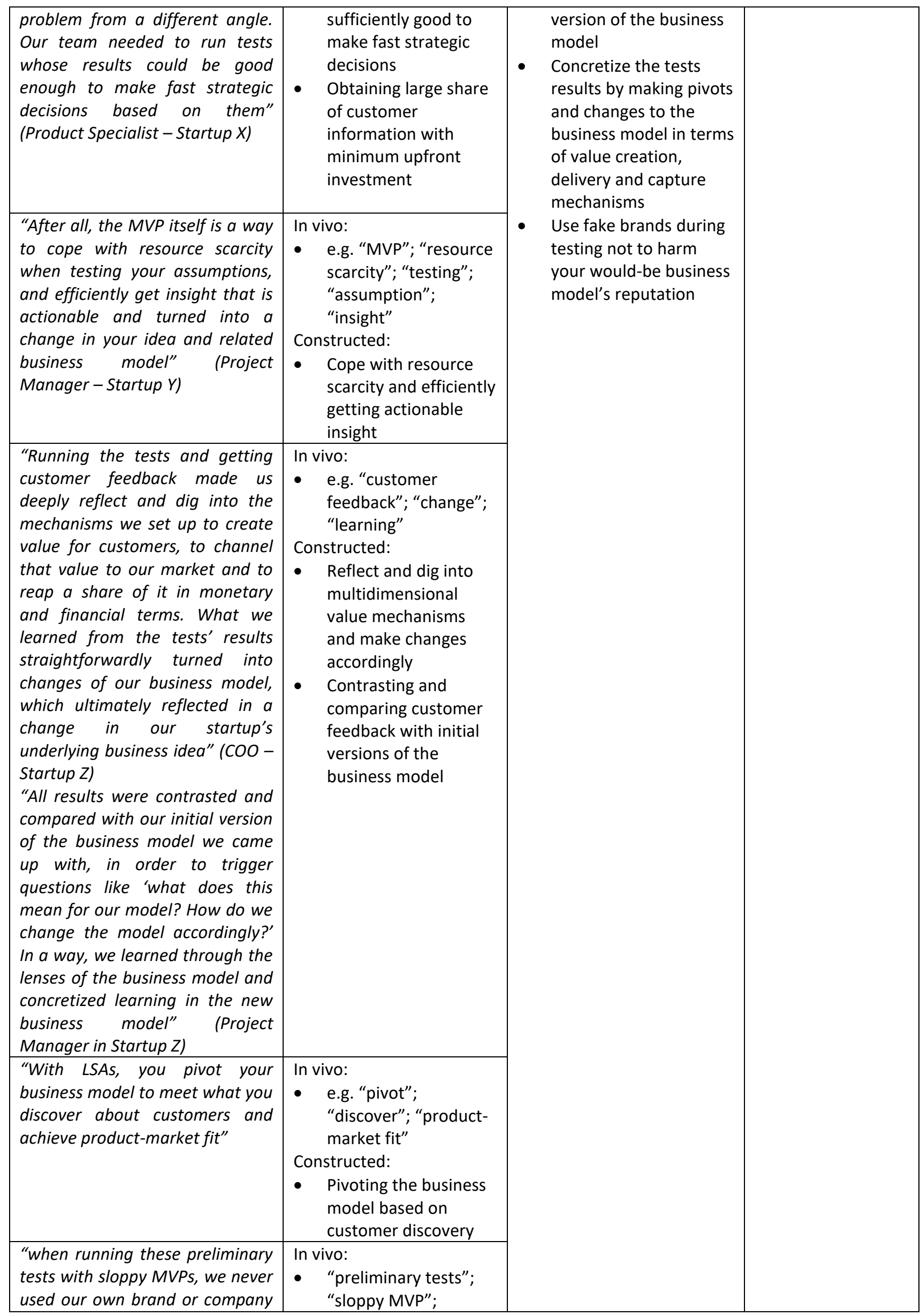




\begin{tabular}{|l|c|l|l|}
\hline name - we'd have been crazy to & "brand"; "fake & \\
do so! We came up with 'fake & brand"; "risk"; & \\
brands', so to limit the risk of & "reputation" & \\
harming our business model's & Constructed: & \\
reputation once we actually & - Protecting business & \\
launched it in the market" & model's reputation \\
(Project Manager-Startup Z) & through fake brands & & \\
& during testing & & \\
\hline
\end{tabular}

Beyond identifying the BM-generated heuristics, our findings disclose an integrative set of cognitive processes that mold and blend the heuristics together, namely:

1. cognitive imprinting;

2. common language transfer;

3. attention intensity; and

4. scientific and experimental cognition.

Table 9 reports our findings on these four cognitive processes.

Table 9 - Results on cognitive processes

\begin{tabular}{|c|c|c|}
\hline Representative quotes & Codes & Cognitive processes \\
\hline $\begin{array}{l}\text { "a few years ago I had a first, brief } \\
\text { experience as would-be entrepreneur } \\
\text { in an incubator, and I was taught to } \\
\text { use the business model canvas to } \\
\text { better explain my idea to investors. I } \\
\text { guess that stuck up in my brain } \\
\text { [laughs]" (CEO - Startup Z) }\end{array}$ & $\begin{array}{l}\text { In vivo: } \\
\text { - e.g. "experience”; “incubator"; } \\
\text { "business model canvas"; } \\
\text { “explain”; “investor”; “brain” } \\
\text { Constructed: } \\
\text { - Past experience on business } \\
\text { model design stuck up in } \\
\text { entrepreneur's brain }\end{array}$ & \multirow[t]{2}{*}{ Cognitive imprinting } \\
\hline $\begin{array}{l}\text { "I picked the RCOV framework since I } \\
\text { learnt it during an innovation contest } \\
\text { I partook in } 3 \text { years ago" (CEO - } \\
\text { Startup Y) }\end{array}$ & $\begin{array}{l}\text { In vivo: } \\
\text { - } \quad \text { e.g. "RCOV"; “learnt"; } \\
\text { “innovation contest" } \\
\text { Constructed: } \\
\text { - } \quad \text { Prior knowledge on the RCOV } \\
\text { business model framework } \\
\text { learnt during an innovation } \\
\text { contest experience }\end{array}$ & \\
\hline $\begin{array}{l}\text { "[CEO name] was always talking } \\
\text { about this canvas thing, value } \\
\text { proposition, segments... at that time I } \\
\text { didn't know exactly what he was } \\
\text { referring to... what I was good at was } \\
\text { software coding...; but after a while I } \\
\text { got it, and all of our early discussions } \\
\text { were on the canvas elements. We } \\
\text { kind of started sharing a common } \\
\text { language to understand one } \\
\text { another" (Product Specialist - } \\
\text { Startup Z) }\end{array}$ & $\begin{array}{l}\text { In vivo: } \\
\text { - e.g. "canvas"; "software coding"; } \\
\text { "early discussions"; "sharing a } \\
\text { common language"; } \\
\text { "understand one another" } \\
\text { Constructed: } \\
\text { - Business model as business } \\
\text { made understandable to people } \\
\text { with non-business background } \\
\text { Business model canvas as shared } \\
\text { common language (Z) }\end{array}$ & \multirow[t]{2}{*}{ Common language transfer } \\
\hline "We tried to map our idea through & In vivo: & \\
\hline
\end{tabular}




\begin{tabular}{|c|c|c|}
\hline $\begin{array}{l}\text { different models, like Maurya' Lean } \\
\text { Canvas, but eventually we picked the } \\
\text { Business Model Canvas as we found } \\
\text { it was easier to communicate it to } \\
\text { investors" (CEO - Startup Z) }\end{array}$ & $\begin{array}{l}\text { - e.g. "different models"; "easier } \\
\text { to communicate"; "investors" } \\
\text { Constructed: } \\
\text { - Business model canvas as } \\
\text { communication means with } \\
\text { investors }\end{array}$ & \\
\hline $\begin{array}{l}\text { "there was a lot going on at the } \\
\text { same time, too many things nudging } \\
\text { us, pushing and pulling here and } \\
\text { there... so it was good to have a } \\
\text { chart to look at, reminding us about } \\
\text { what was important and what } \\
\text { needed to be done" (CEO - Startup X) }\end{array}$ & $\begin{array}{l}\text { In vivo: } \\
\text { - e.g. "a lot going on"; “too many } \\
\text { things"; "chart"; "reminding"; } \\
\text { "important" } \\
\text { Constructed: } \\
\text { - business model as cognitive } \\
\text { reminder for important goals } \\
\text { and tasks }\end{array}$ & Attention intensity \\
\hline $\begin{array}{l}\text { "By moving through LSAs steps and } \\
\text { the development of our startup's } \\
\text { business model they determined, I } \\
\text { and my team gradually learnt how to } \\
\text { approach and tackle problems } \\
\text { systematically, by setting } \\
\text { hypotheses, designing experiments, } \\
\text { gathering results and learning from } \\
\text { them. Sometimes I felt like our } \\
\text { startup was a lab and we were } \\
\text { scientists tentatively searching for } \\
\text { the right business formula!" (CEO - } \\
\text { Startup Y) }\end{array}$ & $\begin{array}{l}\text { In vivo: } \\
\text { - e.g. "approach and tackle } \\
\text { problems systematically"; } \\
\text { "designing experiments"; } \\
\text { "gathering results"; learning"; } \\
\text { "lab"; "scientists"; "business } \\
\text { formula" } \\
\text { Constructed: } \\
\text { - Startup as a lab } \\
\text { - Entrepreneurs as scientists }\end{array}$ & \multirow[t]{3}{*}{ Scientific and experimental cognition } \\
\hline $\begin{array}{l}\text { "LSAs and their search for a market- } \\
\text { proven business model provided us } \\
\text { with a problem-solving mindset in } \\
\text { shaky environments that was nice } \\
\text { and easy to start with, but could } \\
\text { gradually increase in complexity. The } \\
\text { first iterations and business model } \\
\text { pivots we made were somewhat } \\
\text { gross, even though they did the trick; } \\
\text { eventually, as we aimed at scaling, } \\
\text { we could make growingly fine- } \\
\text { grained experiments with } \\
\text { sophisticated metrics" (CMO - } \\
\text { Startup Z) }\end{array}$ & $\begin{array}{l}\text { In vivo: } \\
\text { - e.g. "problem solving mindset"; } \\
\text { "shaky environments"; } \\
\text { "complexity"; "experiments"; } \\
\text { "sophisticated metrics" } \\
\text { Constructed: } \\
\text { - Problem-solving mindset initially } \\
\text { nice and easy, but gradually } \\
\text { increasing in complexity and } \\
\text { level of detail }\end{array}$ & \\
\hline $\begin{array}{l}\text { "experimenting on the business } \\
\text { model taught us what experimenting } \\
\text { means. [...] we now possess a } \\
\text { testable tool that can guide future } \\
\text { action" (COO - Startup X) }\end{array}$ & $\begin{array}{l}\text { In vivo: } \\
\text { - e.g. "experimenting"; "testable } \\
\text { tool"; "guide future action" } \\
\text { Constructed: } \\
\text { - Business model as testable tool } \\
\text { to guide future experimental } \\
\text { action }\end{array}$ & \\
\hline
\end{tabular}

\section{Results}

\subsection{Business model, opportunity sense-making and falsifiable hypotheses formulation}


Each digital startup was born as an idea turned into a vision: this clearly emerged from the very words of the entrepreneurs interviewed. Although extant entrepreneurship literature has been traditionally focusing on opportunities as the unit of analysis to investigate in the embryonic stages of new venture development (Alvarez and Barney, 2011), presenting a dichotomy between the theories of opportunity discovery (Shane and Venkataraman, 2000) and creation (Sarasvathy, 2001), this study's initial questions concentrated on how these opportunities form ideas in the minds of entrepreneurs. This aimed to spot any cognitive role for the business model in the mental process of making sense of entrepreneurial opportunities.

Entrepreneurs tended to describe the process of vision setting as revelatory, a sort of epiphany or moment of being, where their business idea emerged in an unconscious fashion - rather than being the result of structured analysis or planning. As the CEO of Startup Y argued: "I woke up one day with this idea in mind. Literally, I did not know exactly where it came from, but it started buzzing in my head and I soon understood I couldn't let it go away unless I gave it a try!".

The CEO in Startup X had a similar feeling about how his idea came to life almost out of the blue, though he could retrospectively recollect that it resulted from a combination of his path dependent values, beliefs and personal experience: "I was born and raised in a small city by the sea, but I had to move for working reasons. What I loved there was the simplicity and authenticity you could find everywhere, including the trivial experience of buying fish at the waterfront, straight from the fishermen's boats. In a way, our startups embodies the idea of giving everyone, even those people living far away from the sea, the chance to have the same experience I could live when I was there".

In addition, informants from Startups $X$ and $Y$ described this embryonic stage of opportunity sense-making and idea emergence as fuzzy and frantic.

Interestingly, the CEO in Startup Z had a similar revelation concerning his idea about mystery shopping, but reconstructed a different cognitive path upfront, as he started making sense of the opportunity and embody it in the original idea he came up with. "From the very beginning, as I strived to get my idea down to earth, I almost automatically started reasoning in terms of value. I kept asking myself: 'Ok, but what's the value for companies getting my services? What's the value for shoppers? And what's the value for me?' I was basically trying to build a first sketch of a business model in my mind".

Once ideas were clarified, the entrepreneurs in the three startups entered the process of applying Lean Startup Approaches, and learnt that they needed to translate their ideas into falsifiable hypotheses. All the cross-case informants agreed that this initial step was less straightforward than they could expect, but the business model significantly supported their mental process.

As the COO from Startup X explained, "LSAs require you to clearly state the assumptions backing your business idea. As Steve Blank suggests, we did that through the business model construct. So, our overarching assumption that sounded like 'customers will buy fish that is delivered to your home straight from the fisherman's boat', and was quite generic, was translated into specific hypotheses like 'we assume fish shall be clean', 'we assume customers will pay a premium price for this online service', 'we assume our packaging must be fancy', and so on". So, the BM was employed as a cognitive instrument to pass from generic to specific, testable assumptions.

The use of the BM to cognitively support opportunity sense-making and falsifiable hypotheses formulation was remarkably expressed by the words of the CEO in Startup Z: "the BM helped us in better perceiving and giving form to opportunities around a set of hypotheses. And isn't the business model a comprehensive and 
almost ready-to-go set of hypotheses you make about your startup? When you as an entrepreneur say 'my startup will sell this product, to that market, through those channels and with these ways to engage customers', so you are describing your business model, aren't you actually implying that you assume your startup can do all of those things that way, and these BM assumptions need falsification in the real world?".

The CDO in Startup Y also stressed the role of the business model as a cognitive schema to filter, select and organize limited information: "the business model helped me not being up in the air as I used to be. At that time I didn't have much information and data to rely on, but at least the business model was somewhat telling me where to look at and focus on. Any time I gathered new information, data and knowledge from the outside, or any time one guy in the team had a new idea, we tried to fit it into the BM components we designed before, and strived to make sense of it. [...] we were always looking for consistency between the environment, our business model and its internal components; this way we kept track of our early messy development, and tentatively knew what to go for and what to discard".

Our findings concerning opportunity sense-making and falsifiable hypotheses formulation are reported in Table 5 (Section 3.2).

\subsection{Business model and experimenting and testing design}

After the first LSAs step of clarifying the business idea and formulating falsifiable hypotheses on it was completed, all informants agreed that they had to move to the design of experiments and tests: "this is a key step in the process. It is how you concretize all of your philosophical assumptions and make them testable", as the COO in Startup X summarized. "This is the part of the game when you try to make LSAs actionable and measurable", as the CFO in Startup Y put it.

In this step, LSAs introduce the notorious concept of Minimum Viable Product (MVP), which "[I] picked up as an artifact to obtain the largest share of customer information with the smallest upfront investment. Considering at that time we were almost broke and were bootstrapping everything, I got to say I liked the idea" (from the interview to the CEO in Startup Z).

Interestingly, when referring to the MVP and the design of MVP-related testing, informants kept explicitly or implicitly referring to the notion of 'value', the essence of the BM, which is intended as a startup's value architecture (Teece, 2010): "[...] we needed to make real world experiments on how to create value for customers" (interview to CDO in Startup Y); "we believed we were providing the market with something they cared about and desired, something valuable for them... but that was a mere belief in our mind unless we tested it" (interview to CEO in Startup X); "we had to understand if how we wanted to give them value made sense for them" (interview to CEO in Startup Z); these constitute a selection of quotes underscoring a clear focus on value.

Another important insight that surfaced from the interviews concerning experimenting and testing design was that entrepreneurs involved in this phased realized how the business model helped them focusing on all the intertwined dimensions of value they had to falsify and test. In line with this, thanks to his past experience in a previous idea development, the CEO on Startup Z provided an enlightening comparison: "when I tackled the need to test whether that first idea I had a few years ago could work, I believed the only thing I had to prove was that customers saw the benefits related to it. So I went straight to test the value proposition, I mean, the products and services I wanted to sell. Now that I'm at my second experience with 
startups and I'm more familiar with the Lean Startup, I know I have to test the whole system of value: what I give customers - that is, my solution; how I sell that solution to them; and eventually how much I charge for it and in what way, and whether that compensates my costs".

The $\mathrm{CMO}$ from Startup X reinforced this concept her own way: "even when testing startuppers often make a common mistake: they only think of the product and whether 'customers will love it'. What they initially don't get is that customers don't really fall in love with products for what they are, but they do for how products are marketed and how customers themselves are treated in the process. The business model forces you to take a look at the whole picture in a quick and easy way".

Informants hence agreed that using the BM allowed them to escape a common bias linked to consider value proposition testing of greater importance than other testing - e.g. the go to market strategy - to guarantee the startup's early viability.

The paramount role of the BM even in supporting LSAs' experimenting and testing was well summarized by the CDO in Startup Y: "all of our experiments weren't really on a MVP, minimum viable product; what we experimented on was actually a MVBM, minimum viable business model!".

Table 6 (Section 3.2) summarizes our findings on experimenting and testing design.

\subsection{Business model and prioritizing tests}

When it came to prioritizing experiments and tests to be performed in order to falsify the digital startups' assumptions, informants argued that, again, the BM construct was heavily relied on.

As the COO from Startup X described, "understanding which tests to run first - or to run at all - was a matter of evaluating risk and uncertainty. Those assumptions we made about our startup that were riskier had to be prioritized, in line with the RAT [Riskier Assumption Testing] approach in LSAs. The uncertain ones, which means those we knew little about, had to be tested first. [...] In this process, we performed risk evaluation by benchmarking our hypothesized business model elements with existing business models from other companies that were up and running: if we found some of our hypotheses were already met in extant business models, we assumed they were less risky than hypotheses we could not find anywhere else".

This line of reasoning was to a great extent shared by the CEO in Startup $\mathrm{Y}$ in terms of an example: "when familiarizing with LSAs, we learnt of an example about prioritizing tests that referred to a successful product: Apple's iPod. Allegedly, the falsifiable hypothesis behind the iPod could be formulated as 'customers will pay to download music to listen to in public, when they travel, walk or whatever, and that would lead to profits'. That broad hypothesis could be split into three sub-hypotheses, with different levels of risks associated to them. The first hypothesis was that people would listen to music in public, and at the time Apple was developing the iPod, it had already been validated by the business model behind Sony's Walkman. The second hypothesis was about customers willing to freely download digital music, and again, it had been previously validated by Napster and other file sharing business models. The third hypothesis was that customers would be willing to pay for digital music: since digital music was shared peer-to-peer at that time, this assumption was the riskiest one, and needed testing. In fact, the elements in the iPod's business model that needed testing were those related to revenue streams, which eventually led to the smart decision to let people buy single songs for 0.99 \$ or so. [...] To make a long story short, this real-world 
example shows how you prioritize tests: you see what's been validated by other startups' business models in the market, and you focus your experiments on what's uncertain as it found no validation yet".

Table 7 (Section 3.2) encompasses our results on test prioritization.

\subsection{Business model and running tests to trigger validated learning}

The fourth and concluding LSAs step informants discussed during their interviews was that of iteratively running tests based on MVPs, gather customer feedback from them and trigger validated learning to decide how to proceed with their startups' business idea.

A finding that surfaced from the empirical analysis was that MVP-based testing led to satisfactory results considering the limited effort put in the process, and this was sufficient to make decisions at a startup's business model level. The Product Specialist in Startup X described this point as follows: "as an engineer, I was looking for robust experiment design leading to possibly optimal solutions. The Lean Startup and Customer Development, coupled with an evident shortage in resources like time, money, information and people, made me look at the problem from a different angle. Our team needed to run tests whose results could be good enough to make fast strategic decisions based on them".

Consistently with this claim, the Project Manager in Startup $Y$ explicitly related testing outcomes with changes in the business model: "after all, the MVP itself is a way to cope with resource scarcity when testing your assumptions, and efficiently get insight that is actionable and turned into a change in your idea and related business model".

What informants reinforced even when discussing this step was the need to refrain from focusing on value creation alone, but extend the experiments to other business model elements: the COO in Startup Z stated that "running the tests and getting customer feedback made us deeply reflect and dig into the mechanisms we set up to create value for customers, to channel that value to our market and to reap a share of it in monetary and financial terms. What we learned from the tests' results straightforwardly turned into changes of our business model, which ultimately reflected in a change in our startup's underlying business idea".

And again, as the Project Manager in Startup Z argued, "all results were contrasted and compared with our initial version of the business model we came up with, in order to trigger questions like 'what does this mean for our model? How do we change the model accordingly?' In a way, we learned through the lenses of the business model and concretized learning in the new business model".

This statement also emphasized that the business model construct became the object of the startups' pivoting process, and changes were tightly coupled with the BM elements: "with LSAs, you pivot your business model to meet what you discover about customers and achieve product-market fit", as the CEO from Startup X argued.

From the semi-structured interview to Startup Z's Project Manager we also grasped another intriguing tweak entrepreneurs introduce when executing their LSAs' experiments: "when running these preliminary tests with sloppy MVPs, we never used our own brand or company name - we'd have been crazy to do so! We came up with 'fake brands', so to limit the risk of harming our business model's reputation once we actually launched it in the market". 
Table 8 (Section 3.2) organizes our findings on running tests to trigger validated learning.

\subsection{Cross findings on LSAs cognitive processes}

The empirical investigation also allowed to obtain cross findings that were not strictly related with specific LSAs steps, but disclosed other relevant cognitive processes surfacing as digital entrepreneurs approached LSAs.

A first cognitive process that affected how the business model was individually learnt and retained by entrepreneurs is the one we label 'cognitive imprinting'.

When asked to reflect on why he was relying on the BM concept explicitly, the CEO in Startup Z connected his approach to an insightful past experience: "a few years ago I had a first, brief experience as would-be entrepreneur in an incubator, and I was taught to use the business model canvas to better explain my idea to investors. I guess that stuck up in my brain [laughs]". Similarly, the CEO in Startup Y claimed he selected the Resources, Competences, Organization and Value Proposition (RCOV) framework from Demil and Lecocq (2010) as a Business model representation due to his prior knowledge of that tool from an innovation contest.

A second cognitive process surfaced which influenced how the business model and its related heuristics were transferred and learnt by the whole organization is that of 'common language transfer'. Indeed, case $Z$ lets another insightful element emerge concerning BM transferring and organizational learning. The CEO recalled that when he first discussed his idea with a colleague and a friend - where the latter would have become the startup's Product Specialist - he could not escape from explaining it in business model terms. As the Product Specialist stated, "[CEO name] was always talking about this canvas thing, value proposition, segments... at that time I didn't know exactly what he was referring to... what I was good at was software coding...; but after a while I got it, and all of our early discussions were on the canvas elements. We kind of started sharing a common language to understand one another".

Also, when it came to selecting which specific BM construct to adopt among a plethora of different alternatives, informants provided diverse answers. The CEO in Startup Y said he and his team applied the Business Model Canvas (Osterwalder and Pigneur, 2010), following the guidelines provided in Blank (2013). The entrepreneurial team in Startup Z got to the same conclusion, although with a less streamlined path: as the CEO stated, "we tried to map our idea through different models, like Maurya' Lean Canvas, but eventually we picked the Business Model Canvas as we found it was easier to communicate it to investors".

A third crosscutting cognitive process referred to 'attention intensity', that we intend as the cognitive effort and persistence (Ocasio, 1997; Li et al., 2013; Frankenberger and Sauer, 2019) entrepreneurs apply when performing a given task - they previously focused their attention on - over time. As emerging from the interview to the $\mathrm{COO}$ in Startup X, "there was a lot going on at the same time, too many things nudging us, pushing and pulling here and there... so it was good to have a chart to look at, reminding us about what was important and what needed to be done". Hence, a cognitive process of sustaining attention on key steps and goals disentangled throughout the LSAs application, enabled by the BM as a 'cognitive reminder'.

A fourth and concluding cognitive process emerged that we termed 'scientific and experimental cognition', which unraveled how LSAs serve as a 'gatekeeper' to the embracement of a scientific method to 
entrepreneurship. When it came to validated learning enabled by LSAs, some informants shed light on additional insights concerning what the LSAs process as a whole and the use of the business model in it meant for them and their entrepreneurial team.

The CEO from Startup Y claimed that “by moving through LSAs steps and the development of our startup's business model they determined, I and my team gradually learnt how to approach and tackle problems systematically, by setting hypotheses, designing experiments, gathering results and learning from them. Sometimes I felt like our startup was a lab and we were scientists tentatively searching for the right business formula!".

This evidence was supported by a direct quote from the CMO in Startup Z: "LSAs and their search for a market-proven business model provided us with a problem-solving mindset in shaky environments that was nice and easy to start with, but could gradually increase in complexity. The first iterations and business model pivots we made were somewhat gross, even though they did the trick; eventually, as we aimed at scaling, we could make growingly fine-grained experiments with sophisticated metrics".

A concluding remark from the $\mathrm{COO}$ in Startup X reinforced the importance of the BM for the whole learning process and the following startup's development: "experimenting on the business model taught us what experimenting means. [...] we now possess a testable tool that can guide future action".

\section{Discussion}

The analysis, coding and cycling between existing theory and empirical evidence shed light on a number of issues that connected to the cognitive approach digital entrepreneurs have when applying LSAs, and how they make use of the business model concept and construct within this context.

Our overarching findings are corroborated by the activity of contrasting and comparing evidences surfacing from the case with extant theory on heuristics and simple rules (e.g., Gigerenzer and Brighton; 2009; Bingham and Eisenhardt, 2011; Gigerenzer et al., 2011; Look and Hinnen, 2015; Gigerenzer, 2016; Bingham et al., 2019).

This study's within-case and cross-case investigation finds that digital entrepreneurs embarking in LSAs consistently use the business model as cognitive lenses to filter abstract LSAs guidelines and translate them into more concrete and pragmatic heuristics; these resulting heuristics are fast and frugal, since they are accurate in exploiting relevant information coming from both within and outside of the organization, and cognitively efficient in translating and specifying generic information to enable inference and action.

Through the combination of two generative cycles of sense-making and specification, the business model gives rise to a set of 'first-order (i.e. more abstract and generalized) heuristics', used in turn to generate 'second-order (i.e. more concrete and specific) heuristics' through the cognitive lenses it equips entrepreneurs with.

Ultimately, it is by means of the BM that entrepreneurs cognitively make sense of Lean Startup Approaches and prepare themselves for opportunity capture through experimentation.

Making sense of LSAs through the BM-mediated simple rules is also assisted by a set of four crosscutting cognitive processes which act on the BM to mold and blend the heuristics together, namely (i) cognitive 
imprinting, (ii) Common language transfer; (iii) attention intensity and (iv) scientific and experimental cognition.

The discussion of our findings is organized in two parts, revolving around: (i) the business model-generated first and second-order heuristics; and (ii) the cognitive processes explaining how the BM-generated heuristics are learnt, transferred, enacted and employed as enabler of an overall scientific process to entrepreneurship.

\subsection{Business model-generated first and second-order heuristics}

The BM first-order heuristic of "opportunity sense-making" generates second-order heuristics that refer to the employment of the business model as a cognitive map to help entrepreneurs in perceiving and giving form to opportunities, which arise for how entrepreneurs perceive reality rather than for what it actually is. The BM hence becomes a category to interpret entrepreneurial creativity, superior insight or revelations (Hitt et al., 2001), typical of an opportunity seeking or creating behavior (Shane and Venkataraman, 2000; Sarasvathy, 2001), and systemically shape it into an architecture. Such architecture is beneficial to entrepreneurs as it fosters an upfront focus on value (Teece, 2010) and calls for internal consistency within the multiple dimensions and mechanisms of that value (Rappa, 2001; Foss and Saebi, 2017; Teece, 2018). Our cases show that digital startups employed the BM-generated heuristics to move from the fuzziness of their perceived opportunity to the business to a higher level of clarity, without a too burdening cognitive complexity - since in this stage the BM was more of a stylized form. This finding is in line with the Gestalt view on BMs proposed in Loock and Heckert (2015), where BMs give form to perception.

After the startups made sense of their opportunities to create a multisided platform for selling fish online (case $\mathrm{X}$ ), create an electronic wallet to manage savings (case $\mathrm{Y}$ ), or create a digital platform to offer mystery shopping services, they turned to the "hypothesizing" BM-generated first-order and second-order heuristics to further specify those opportunities. The largest share of empirical evidence concerning the use of the BM concept and construct refers to this step, since later versions of LSAs hint at the use of the BM canvas tool when formulating hypotheses. Indeed, these heuristics helped entrepreneurs to translate generic opportunities and business ideas into specific and testable assumptions. Setting falsifiable hypotheses about the startup would be a difficult task with no preordained or pre-existing basis, and entrepreneurs caught up in the void of early stage development would tend to leapfrog this activity (Ghezzi, 2019) without a cognitive point of reference. Therefore, the BM lens - with specific reference to the BM canvas for cases $X$ and $Z$, and the RCOV framework for case $Y$ - helped generating heuristics to formulate falsifiable hypotheses, as it encompasses a set of assumptions about the startup and its context that the entrepreneur formulates, often implicitly, on how the startup would respectively create value for its customers, deliver that value to the market and capture a share of it in terms of profits. Through a heavy reliance on the notion of value, the business model heuristics evidently push digital startups to adopt a value-centric and customer-centric perspective, providing simple rules or reminders to always put customer value at the center of the entrepreneurial equation from its very beginning. This is in line with the reconciling power the BM has according to Demil and colleagues (2015) and Massa and colleagues (2017): we find strong evidence that BM-generated heuristics help entrepreneurs manage the tensions between supply-side and demand-side elements that determine the survival and success of their entrepreneurial endeavor. 
Using the $\mathrm{BM}$ as cognitive lens also provided entrepreneurs with a fast and frugal rule to focus their attention in uncertain and turbulent times like those of early-stage startup development: the BM was leveraged to target entrepreneur's attention - a resource whose importance and scarcity is often overlooked (Ocasio, 1997) - and time in the validation process on parameters that mattered. This is consistent with the effectuation and bricolage entrepreneurial logics (Sarasvathy, 2001; Baker and Nelson, 2005), as well as with the findings from Frankenberger and Sauer (2019) on the role of attention focus as a BM design cognitive antecedent.

Once hypotheses are formulated and attention is clearly directed, the BM is leveraged to perform the essential activities of "filtering, selecting and organizing": the heuristics help as a cognitive schema to filter, select and organize limited and unstructured information coming from both the outer world and the internal entrepreneurial team - often so eager to be creative and come up with new perspectives even after the initial business idea is formed; in line with the fast and frugal paradigm in heuristics, in this step the BM-generated heuristics allow entrepreneurs to discard irrelevant information that may determine a cognitive overload (Gigerenzer and Brighton, 2009), on the basis of their fit and consistency with the business model assumptions hypothesized. The evaluation of information fit leads to their organization around BM parameters: this is consistent with Bingham and Eisehnardt's (2011) claim that heuristics provide a "common structure for a range of similar problems, but supply few details regarding specific solutions to address them" (Bingham and Eisenhardt, 2011: 1439). Heuristics hence create value in dynamic environments through coordination and an improved effort/accuracy trade-off (Loock and Hinnen, 2015: 2032). The BM-generated heuristics cognitive architecture - made of intertwined and tightly coupled value elements - permits to adapt to the changing environment while retaining consistency in the overall startup (Bingham et al., 2007; Brown and Eisenhardt, 1997; Loock and Hinnen, 2015).

Entrepreneurs transforming falsifiable hypotheses into experiments again leverage the BM-generated first and second-order heuristics that we call "multidimensional experimenting and testing design": in line with their constant condition of resource scarcity, they start from a Minimum Viable Business Model to design Minimum Viable Products that bootstrap assumptions testing. Here, the fast and frugal nature of these heuristics clearly emerges (Gigerenzer, 2011; 2016), as BM constructs like the BM canvas are surprisingly accurate to depict a value architecture, while avoiding a common entrepreneurial bias that could hinder the validation of the startup's early viability: that is, design experiments to test the value proposition only. The BM-generated heuristics quickly and efficiently remind entrepreneurs to take into fair account not only their product and services, but also essential elements like go to market strategy, channels, customer relationship, costs and revenues.

Alongside the experiment design heuristic, the BM also offers the foundation for "prioritizing" heuristics based on analogical arguments: BMs are cognitive devices to prioritize risk and uncertainty assessment (Tversky and Kahneman, 1975), by stimulating entrepreneurs to contrast and compare the business model's assumptions with other existing companies' or startups' business model, thus assigning a higher priority to those riskiest assumptions no one validated before, while refraining from wasting resources on those assumptions that were already proven right in different contexts. In line with the abovementioned discussion, a BM approach also enforces a "no priority" second-order heuristic for value proposition, so that entrepreneurs can escape what we call the 'value proposition testing fallac'y. Similar dynamics are found in Roessler et al. (2018), who discuss analogical reasoning as a process to antagonize cognitive biases in Corporate Entrepreneurship initiatives; and in McDonald and Eisenhardt (2019), who investigate how startups take interest on and mimic peers' business models in the initial learning phases of a process they 
name parallel play: our findings contextualize these dynamics in the setting of Digital Entrepreneurship and LSAs for BM validation.

The experiments designed and prioritized are then to be run, so as to trigger a validated learning process that impacts the original business idea the startup was built around. Here, entrepreneurs show they used the BM-generated first-order heuristic of "learning processing and concretizing" and its related secondorder heuristics. The outcome of customer discovery (Blank, 2007; Blank and Dorf, 2012), that is, customer feedback, is processed through the lenses of the business model; entrepreneurs then iteratively contrast and compare the tests results with the original version of the business model, and concretize the changes needed by making pivots to the business model in terms of value creation, delivery and capture mechanisms. In addition to this, some specific testing applied by startups, like A/B testing on business model parameters, are close to the concept of recognition heuristic - i.e. selecting one object between two, found in Goldstein and Gigerenzer (2002); this further reinforces our claim that entrepreneurs use BMs as heuristics. Moreover, the second-order heuristic indicating to use 'fake brands' when running preliminary experiments not to harm the future startup's brand (see Table 8) constitutes a fast and frugal heuristic answer entrepreneurs provide to Gans and colleagues (2019), who claim that conducting economic experiments carries opportunity costs for startups, since poorly designed and executed early customer interactions may negatively impact reputation.

Testing on BMs makes processing feedback easier for entrepreneurs, since BM is encoded in a simple way though straightforward constructs. Also, the BM as cognitive lens creates preordained cognitive links among different information, facilitating more sophisticated learning (Bingham and Eisehardt, 2011: 1452); a business model perspective helps entrepreneurs move from isolated learning - which is typical of novices - to holistic learning - a feature of expert learning. As Baron and Ensley (2006) find, expert entrepreneurs concentrate their attention on customer problems: an activity the business model is specifically designed to enable.

\subsection{Cognitive processes}

To further extend the discussion above, a set of themes emerging from the multiple case study did not add up to form heuristics entrepreneurs use as simple rules, although they provided rich insight on the cognitive processes that mold and blend together the BM-generated heuristics.

Our findings shed light on how business models are learnt by entrepreneurs. Consistently with the recent theory on entrepreneurial imprinting (e.g. Bryant, 2014; Mathias et al., 2015), we infer that exposure to the BM in previous experiences creates a "cognitive imprinting": once an entrepreneur learns about the BM and how to use it, it becomes difficult to refrain from using it. We also found that business models imprint during "sensitive periods of transition" (Mathias et al., 2015), like a previous experience as a would-be entrepreneur (case Z) or the participation to an innovation contest (case X); these periods represent sources of cognitive imprint for entrepreneurs, which influence future action and performance in the venture. Indeed, while the entrepreneurs claim the BM concept and construct got "stuck up" in their mind, they also argue it stayed with them and influenced future behavior and action. We may then argue that the BM as heuristics features cognitive "stickiness".

Cognitive imprinting and stickiness also enable business models heuristics transfer throughout the heterogeneous team as a "common language", resulting in a consequent organizational learning that possibly moves the role of heuristics from individual to organizational (Loock and Heinen, 2015). 
Consistently with this, the Product Specialist in Startup X - who initially worked as a software developer defined the business model as "business made understandable to techy nerds [laughs]": BM-generated heuristics are easy to grasp and remember, which makes for knowledge retention and learning (Baddeley and Hitch, 1974). Although the limited startup's size in terms of number of people and resources may simplify heuristics' transferability, since organizational and individual learning are almost equivalent in entrepreneurial firms (Bingham and Eisenhardt, 2011: 1443), whether the cognitive imprinting and stickiness we found in our study would enable transferability even in larger organizations sets an interesting avenue for future research. Concerning heuristics transfer, our study also confirms that the business model encompasses a set of rules and principles facilitating non only intra-founding team, but also inter-team communication with third parties, such as investors; this confirms the frugality of the business model heuristics (Loock and Hinnen, 2015: 2034).

Another interesting insight relates to the cognitive process of attention intensity: notwithstanding uncertainty, emerging elements and unexpected occurrences 'nudging' entrepreneurs and possibly moving them away from their targeted goal of business idea's validation, entrepreneurial attention was sustained throughout the LSAs application process thanks to the persistence of the BM - in the form of BM-generated heuristics - in all of its steps. The fact that all heuristics practiced by the entrepreneurs had a common origin and showed strong mutual consistency represented a sort of 'cognitive reminder' to maintain focus over time (Ocasio, 1997; Li et al., 2013; Frankenberger and Sauer, 2019).When it comes to BM heuristics enactment, the interviews allowed to infer that entrepreneurs relied on the business model as sort of an Ockham razor, a "law of parsimony" to filter complexity and turn that into simplicity and clarity. This is mostly evident with reference to opportunity sense-making and information filtering. In this sense, entrepreneurs find in the business model a supportive cognitive companion in their natural tendency to favor simplicity over complexity. Such tendency is also in line with the primary objective entrepreneurs should set in their early stages of startup development: hypotheses falsification. As Popper (1992) argues, the falsifiability criterion makes individuals prefer simple theories to more complex ones as the former's empirical content is greater, and because they are better testable. Entrepreneurs are hence prone to cognitively embrace BM-generated heuristics as they perceive their value in engaging startup validation in a simple way.

Still, the simplicity the BM exhibits is that of a "recipe" (Baden-Fuller and Morgan, 2010), which is simple enough to be actionable, but can grow in complexity as the startup's resources accruing over its lifecycle allow it. AS the CEO in Startup Y put it, "at a first glance the BM canvas looks simple. But once you scratch the surface, you find it's a thick concept".

The BM concept and constructs thus help entrepreneurs move from fuzziness to clarity, by means of experimenting and testing that offers "satisficing" results (Simon, 1947), which are good enough to trigger a learning process and make initial pivots, but that can be optimized later on. The BM-based testing makes for a fast and frugal decision making, as startups surfing on the "edge of chaos" (Brown and Eisenhardt, 1998) need simple rules to decide their course of action.

Hence, BM-generated heuristics as rules of thumb are not mere "crude guesses" (Bettis, 2017: 2620), and can help entrepreneurs tackling uncertain problems related to creating an organization, as they help strategist address intractable problems - i.e. problems where the total time required to reach a rational and analytical conclusion is so long that in the meantime the setting has changed or the problem has become irrelevant - when making the organization advance and perform in a competitive environment. 
Using BM heuristics to manage tensions and tradeoffs between simplicity and complexity, fuzziness and clarity, cognitive frugality and computational rigor, also reveals how BM-generated heuristics could mend such tensions and enable a smoother migration from a lean to a more scientific method backing entrepreneurial endeavors, thus stimulating a scientific and experimental cognition.

LSAs and their search for business model validation through customer discovery provides entrepreneurs with a problem-solving mindset that was "nice and easy" to start with, but could gradually increase in complexity (Baden-Fuller and Morgan, 2010). When asked about the value of LSAs as a whole, entrepreneurs offered insightful parallelisms between startups and labs, and entrepreneurs as scientists; they also revealed that these lean approaches fundamentally taught them how to test on the business model, and that approach could be replicated with more fine-grained experiments and sophisticated metrics as the startup would need to grow and scale up.

As a result, our study confirms that heuristics, and in our case the first and second-order heuristics stemming from the BM's cognitive lens, facilitate accurate decision making in the startup context which involves uncertainty (Gigerenzer, 2014; Loock and Hinnen, 2015). What we add is that the BM heuristics are scalable in complexity, and could play as both relatively simple heuristics in the startups' uncertain context, and complex model when the startup scales and enters a risky context (Bingham et al., 2019): the BM heuristics can hence smoothen the entrepreneurial mental transition from effectuation to causation settings, where the latter require more cognitive demanding approaches and artifacts, like the business plan (Ghezzi, 2019).

Therefore, BM-generated heuristics in the LSAs setting play a gatekeeper role to a transition towards a more scientific approach to Entrepreneurship based on rigorous experimenting and sophisticated metrics. To some extent, this finding also provides a reply to Blank's (2018) argument according to which, in an entrepreneurial ecosystem currently awash with capital, startups may not need the Lean Startup: our study reveals that even in a context were resources are not that constrained, startups still find benefits in what they learnt from BM-generated heuristics when adopting LSAs, by turning this knowledge into a scientific entrepreneurial process suitable for scaling.

A further reflection on the role of BM as cognitive lens to generate heuristics refers to the discussion on entrepreneurial opportunities. Our findings allow to infer that the opportunity sense-making first-order heuristic acts as opportunity-creation heuristics, more than opportunity-capture heuristics (Bingham and Eisenhardt, 2011). Before being strategically-rational, BM-generated heuristics are entrepreneuriallycreative, as the BM helps entrepreneurs in funneling creativity in a model that enables experimenting. In line with Bingham and Eisenhardt (2011), startups then engage in transforming their portfolio of heuristics, which move from being entrepreneurially creative to strategically rational as the BM itself is validated and the startup shifts from a more entrepreneurial, opportunity-seeking to a more strategic or advantageseeking behavior. This consideration may extend the results from Bingham and Eisenhardt (2011) uphill, as the authors investigated more consolidated new ventures as they internationalized, while we concentrated on startups in their earlier stages of development: heuristics cycling for new ventures could then start with entrepreneurially-creative heuristics that are gradually turned into strategically rational, as the new venture changes its overarching behavior from an opportunity-seeking to an advantage-seeking one (Shane and Venkataraman, 2000; Hitt et al., 2001). The fil rouge connecting these stages is again the business model, which reconnects strategy with entrepreneurship (Demil et al., 2015) and sets the scene for the Strategic Entrepreneurship field. 


\subsection{How Entrepreneurs cognitively make sense of Lean Startup Approaches: a model}

Our discussion of the study's findings can be conceptualized in a model that accounts for how entrepreneurs cognitively make sense of Lean Startup Approaches when committed to apply them to their business idea and related startup (see Figure 1).

Figure 1. How entrepreneurs cognitively make sense of Lean Startup Approaches through the business model

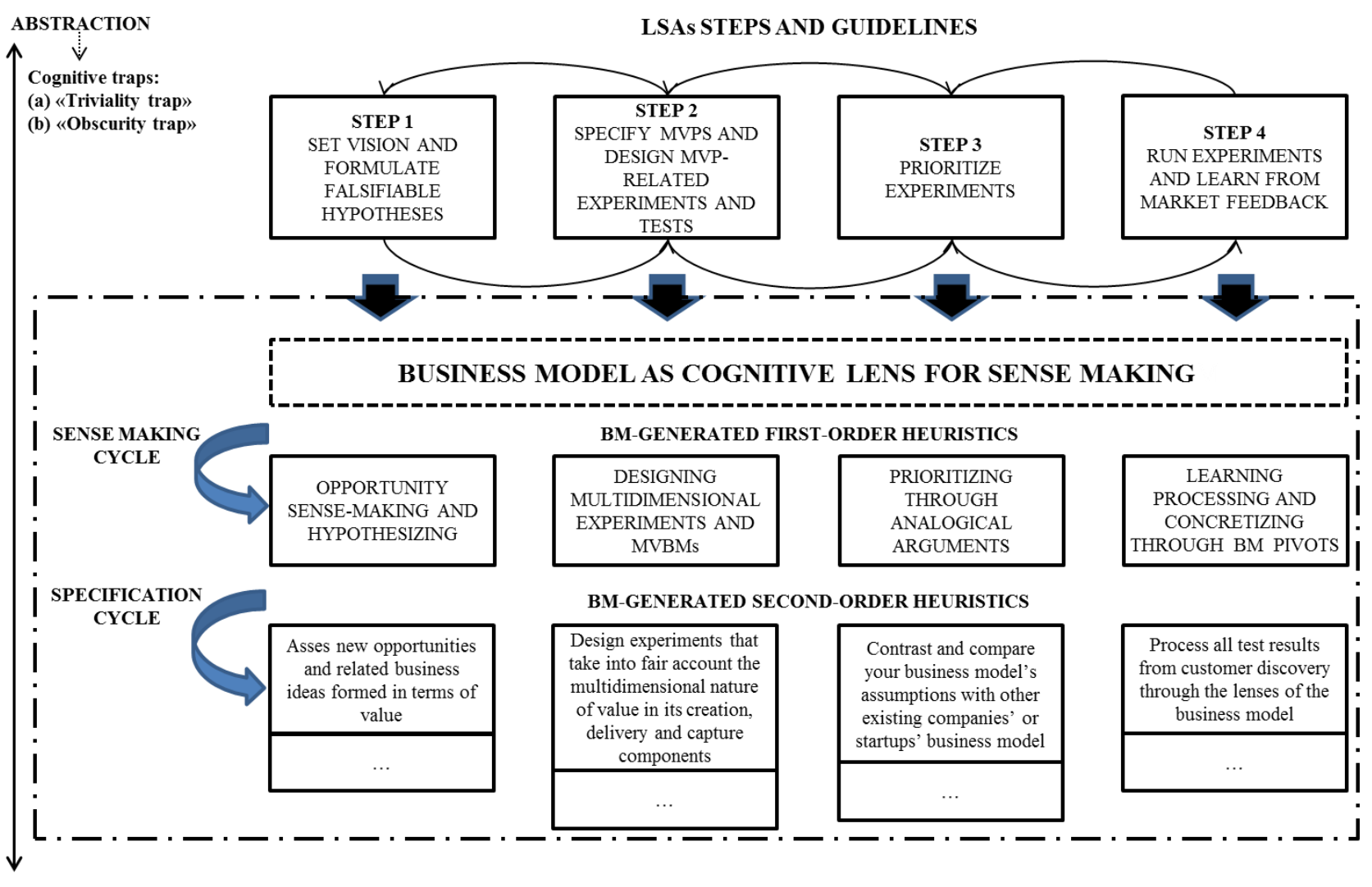

Our model depicts as an upper level the four main LSAs steps as they are preached by extant literature: (1) set a vision and translate it into 'falsifiable hypotheses'; (2) specify Minimum Viable Products (MVPs) and design MVP-related experiments and tests; (3) prioritize experiments; and (4) run experiments and learn from market feedback. These steps are understood by entrepreneurs as a sequence of iterations, allowing for feedback and feedforward cycles.

As the entrepreneurs cognitively approach LSAs steps, they attempt to translate those steps into actionable guidelines, such as 'formulate hypotheses', 'craft MVPs', 'design and run experiments'. Still, being such guidelines they straightforwardly derive from the steps rather abstract and unspecific, entrepreneurs may perceive each step as either apparently trivial - e.g. the vision is equated to the business idea, and entrepreneurs believe they already have one - or rather obscure - e.g. the MVP is a complex concept to conceptually convey and concretize with no exemplification.

In this initial phase, we argue that entrepreneurs wander in a cognitive region delimited by triviality and obscurity, both undesirable conditions which respectively hide what we label (a) triviality trap- i.e. the 
guideline seems so easy to understand that the entrepreneur almost takes it for granted and devotes little to no cognitive effort to pragmatically pursue it - or (b) obscurity trap - i.e. the guideline appears so complicated to understand that the entrepreneur is cognitively blocked and decides to either skips it and move to the next one, or halt and possibly abandon the process altogether.

In order to possibly escape both triviality and obscurity cognitive traps, the entrepreneurs resort to use the business model as cognitive lens to make sense of LSAs' guidelines, thus making such guidelines more specific and pragmatic. This BM-mediated sense-making process is enacted through a sort of cognitive imperative entrepreneurs should comply with: whenever attempting to understand and implement LSAs' steps and guidelines, do so through the business model.

In detail, this means that during step (1) of LSAs, entrepreneurs have to: make sense of opportunities through the BM; hypothesize through the BM; focus their attention on the BM; and filter, select and organize information and knowledge around the BM. During step (2), the design of multidimensional experiments and tests should be performed based on the BM; while in step (3), experiments should be prioritized through analogical arguments that compare the startup's expected BM with competitors'; and eventually, in step (4), learning obtained through experimentation should be processed and concretized in BM terms (e.g. BM pivots). These rules of thumb constitute a first set of BM heuristic guiding entrepreneurs cognition.

Intriguingly, this use of the business model for cognitive sense-making is not local (as the original versions of Lean Startup and Customer Development would seem to imply), but pervasive and spread throughout the LSAs steps.

As repetitive as it may sound, setting this cognitive imperative serves as a 'pole star' to support entrepreneurs' orientation through uncertainty, in order to escape triviality and obscurity traps; a sort of memento according to which, irrespectively of any emerging stimulus or unexpected occurrence, their paramount goal when applying LSAs is to obtain BM validation.

The use of the BM as lens to make sense of LSAs gives rise to a set of first-order heuristics entrepreneurs should follow (see the last columns in Tables 5, 6, 7 and 8), all based on the cognitive imperative 'do so through the business model'. However, these heuristics' level of abstraction may still be cognitively troublesome in terms of effective understanding and implementation: for instance, the BM-based heuristic supporting step (3), which tells managers to prioritize experiments by finding any differences between the startup's would-be BM and the competitors' extant BMs, may puzzle entrepreneurs attempting to operationalize this first-order rule into actual experiments ranking - once analogies are found, what does that imply in terms of priorities?

Therefore, based on each first-order BM heuristics, entrepreneurs generate more fine-grained and specific second-order heuristics (see the third columns in Tables 5, 6, 7 and 8), thus completing the translation of abstract LSAs guidelines into pragmatic simple rules. For instance, going back to the abovementioned example, the BM-generated first-order heuristic to analogically compare BMs to prioritize experiments is further specified into second-order heuristics, like 'select and prioritize assumptions that have not been tested and validated by existing companies' or cognitive shortcuts startups' business models, since these assumptions are the riskiest', 'assign a lower priority to assumption already validated in existing business models' and 'do not assign any priority a priori to value proposition tests' (see Table 7 - third column). 
As a whole, the role of the BM as cognitive lens for making sense of LSAs is enacted through two cycles: a first sense-making cycle, which help entrepreneurs understanding LSA abstract guidelines in BM-terms and related first-order heuristics; and a second specification cycle, which further translates first-order heuristics or simple rules into second-order ones.

Moving from the upper to the lower level of our model pictured in Figure 1, we shift from high cognitive abstraction - found in general LSAs guidelines - to high concreteness - represented by BM-generated second-order heuristics.

Our model is completed by the inclusion of the four cognitive processes of (i) cognitive imprinting, (ii) Common language transfer; (iii) attention intensity and (iv) scientific and experimental cognition (see Table 9), that act on the BM to mold and blend together its heuristics throughout the LSAs steps, explaining how they are learnt, transferred, enacted and persistently employed as enabler of an overall scientific approach to entrepreneurship.

As displayed in Figure 2, (i) cognitive imprinting enhances the role of the BM as a cognitive lens for sense making by turning it into a sticky and easy to remember construct; this also makes for its transfer as a common language (ii) both within the entrepreneurial team and outside of the team, when interacting with third parties. Attention intensity (iii) works as a cognitive reminder to concentrate on customer centricity and the value logic throughout the process and its steps, both vertically - i.e. from general to specific rules - and horizontally - from the first to the last LSAs step. As a whole, an additional outcome is the rise of a persistent scientific and experimental cognition (iv) that will stay with the entrepreneurial team also during the scale up phases or future startup endeavors. 
Figure 2. BM-generated first and second order heuristics and the four cognitive processes

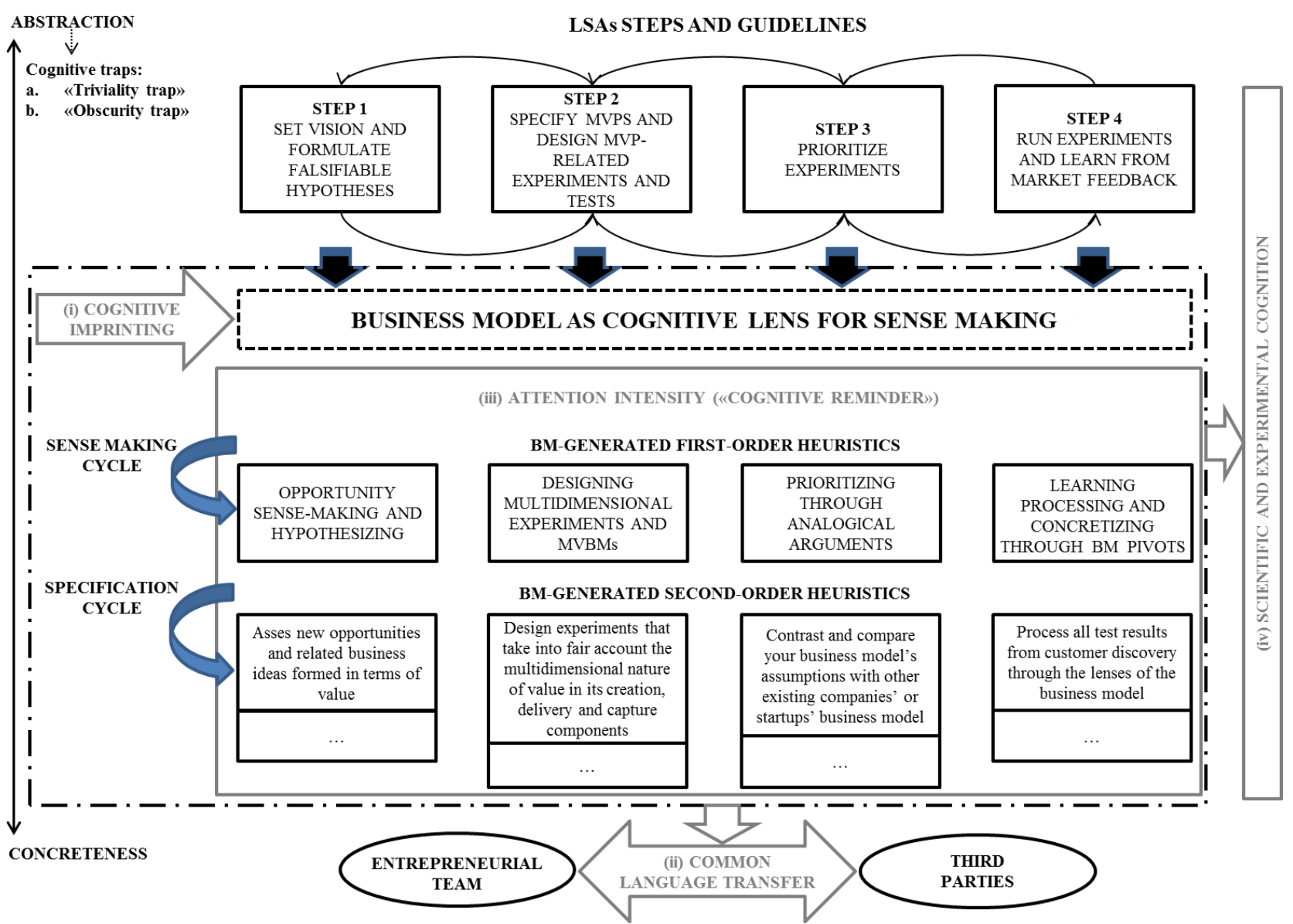

\section{Conclusions}

This study is positioned at the crossroads of business model and heuristics theories, and possibly offers a multifaceted contribution that touches upon the domains of Entrepreneurship and Strategy.

Our primary finding is that digital entrepreneurs make sense of Lean Startup Approaches and translate their rather abstract guidelines into pragmatic rules by means of the business model, used as cognitive lens to generate first and second-order heuristics: this explicit connection and role is currently not found in extant academic and practitioner literature, and constitutes a relevant finding with several implications for theory and practice.

Business model' first-order heuristics generated through a sense-making cycle help entrepreneurs in: (i) making sense of entrepreneurial opportunities; (ii) formulating falsifiable hypotheses concerning their startups' viability; (iii) filtering, selecting and organizing fuzzy and incomplete external and internal information; (iv) designing multidimensional customer experiments and tests revolving around the notion of value, through Minimum Viable Business Models (MVBMs); (v) prioritizing these experiments and tests to validate their early BM through analogical arguments; and (vi) processing the learning they obtain from experiments, and concretizing it in the form of BM pivots. The related second-order heuristics stemming from a specification cycle offer hands-on simple rules driving entrepreneurs' action: the whole system of heuristics is hence kept together by a set of cognitive processes of imprinting, communication transferring, cognitive reminders and persistent scientific and experimental cognition. 
All of this manifests itself in a way that is fully aligned with the "fast and frugal" heuristics paradigm (Gigerenzer et al., 2009; 2011; Loock and Hinnen, 2015): we argue that entrepreneurs use BM-generated heuristics to cognitively make sense and make do (Baker and Nelson, 2005) notwithstanding resource scarcity - which include bounded rationality - and obtain satisficing results concerning their business idea's validation.

The BM-generated heuristics have a common structure throughout the startup cases investigated, but idiosyncratic content; and consistently with Bingham and Eisenhardt (2011), they help the cognitive development of entrepreneurs from novice to expert. At the same time, BM-generated heuristics pave the way for a transition towards a more scientific approach to Entrepreneurship based on rigorous experimenting and sophisticated metrics.

This study's findings concerning the use digital entrepreneurs make of the BM to cognitively make sense of and specify LSAs are consistent with what Loock and Hinnen (2015) find heuristics are valuable to: facilitate accurate decision making under uncertainty; avoid overfitting though simplification, acting as an Ockham's razor; systematically filter, select, organize and utilize information from the external and internal startup's environments; capitalize and concretize learning obtained through customer discovery and experimenting; and allow fast and frugal decision making about persevering with the BM, pivoting it or making it perish.

As a whole, from a theory perspective, our research provides new life to the study of BMs as heuristics, thus reconciling the theories on business model design, innovation and validation with that on heuristics; it adds a recent and relevant empirical context where to accrue knowledge on how heuristics are formed, used and transferred; it offers a new opportunity to frame the LSAs, a set practitioner practices in need for better theory, within the heuristics theoretical stream; and finally, it paves the way for a more explicit inclusion of BM-generated heuristics in the microfoundations discourse in Entrepreneurship and Strategy (e.g. Bingham et al., 2019).

From a practice perspective, our findings pragmatically translate general LSAs guidelines into BM-generated specific rules of thumbs that can come in handy whenever entrepreneurs embark in the customer validation process for their business ideas. In fact, our study tackles a subtle practitioner criticism to the LSAs: the fact that although these methods should be pragmatic, applying their guidelines is somewhat complex for entrepreneurs in need for a 'how to' guide (Ghezzi, 2019). What we find is how exactly the BM helps entrepreneurs in making LSAs' abstract guidelines comprehensible and actionable through specific simple rules. In doing so, the BM assists entrepreneurs in cognitively making do, by orienting their cognitive scarce resources towards the primary aim of an early digital startup: that is, validating its value architecture.

The cognitive imperative whenever attempting to understand and implement LSAs' steps and guidelines, do so through the business model our study puts forward can hence be of significant practical help for entrepreneurs caught up in the void of early stage startup development.

More broadly speaking, this study supplies a case of use of the BM construct as cognitive lens to generate heuristics that impact technological development (Güttel et al., 2018), embodied in digital startups development: this consideration may provide room for generalization of findings to different cases of use of heuristics in technological development. Future research could extend these considerations to technological development endeavors others than digital startups, like innovation processes within incumbent companies. This could lead to the use of BM as heuristics in Corporate Entrepreneurship 
(Burgelman, 1983; Roessler et al., 2018) frameworks, thus connecting to the discourse on heuristics in organizations (Loock and Hinnen, 2015).

\section{References}

Alvarez, S.A., Barney, J.B., (2007). Discovery and creation: Alternative theories of entrepreneurial action. Strategic Entrepreneurship Journal 1 (1-2), 11-26.

Autio, E., Nambisan, S., Thomas, L. D., Wright, M. (2018). Digital affordances, spatial affordances, and the genesis of entrepreneurial ecosystems. Strategic Entrepreneurship Journal 12 (1), 72-95.

Baddeley, A., Hitch, G.J. (1974). Working memory. In Psychology of Learning and Motivation, Bower GA (ed). Academic Press: New York; 47-89.

Baden-Fuller, C., Morgan, M. S. (2010). Business Models as Models. Long Range Planning 43 (2-3), 156-171.

Baker, T., Nelson, R. E. (2005). Creating something from nothing: resource construction through entrepreneurial bricolage. Administrative Science Quarterly, 50 (3), 329-366.

Baron, R.A., Ensley, M.D. (2006). Opportunity recognition as the detection of meaningful patterns: evidence from comparisons of novice and experienced entrepreneurs. Management Science 52(9), 1331-1 344

Bettis, R. A. (2017). Organizationally Intractable Decision Problems and the Intellectual Virtues of Heuristics. Journal of Management 43 (8), 2620-2637.

Bingham, C. B., Eisenhardt, K. M. (2011). Rational heuristics: the 'simple rules' that strategists learn from process experience. Strategic Management Journal 32 (13), 1437-1464. doi:10.1002/smj.965

Bingham, C. B., Eisenhardt, K.M., Furr, N. R. (2007). What makes a process a capability? Heuristics, strategy, and effective capture of opportunities. Strategic Entrepreneurship Journal 1 (1-2), 27-47.

Bingham, C. B., Howell, T., \& Ott, T. E. (2019). Capability creation: Heuristics as microfoundations. Strategic Entrepreneurship Journal 13 (2), 121-153.

Blank, S. (2007). The Four Steps to the Epiphany: Successful Strategies for Products that Win. K\&S Ranch.

Blank, S. (2013). Why the lean start-up changes everything. Harvard Business Review 91 (5), 63-72.

Blank, S. (2018). NewTV Is the Antithesis of a Lean Startup. Can It Work? Harvard Business Review, August 20th, 2018. Last accessed on October 13th, 2018 at: https://hbr.org/2018/08/newtv-is-the-antithesis-of-alean-startup-can-it-work

Blank, S., Dorf, B. (2012). The Startup Owner's Manual: The Step-By-Step Guide for Building a Great Company. K\&S Ranch Consulting.

Bortolini, R. F., Nogueira Cortimiglia, M., Danilevicz, A. D. M. F., Ghezzi, A. (2018). Lean Startup: a comprehensive historical review. Management Decision, forthcoming: https://doi.org/10.1108/MD-07$\underline{2017-0663}$ 
Brown, S. L., Eisenhardt, K. M. (1998). Competing On The Edge: Strategy As Structured Chaos. Boston: Harvard Business Press.

Brown, S. L., Eisenhardt, K.M. (1997). The art of continuous change: linking complexity theory and timepaced evolution in relentlessly shifting organizations. Administrative Science Quarterly 42 (1), 1-34.

Bryant, P. T. (2014). Imprinting by design: The microfoundations of entrepreneurial adaptation. Entrepreneurship Theory and Practice 38 (5), 1081-1102.

Burgelman, R. A. (1983). Corporate entrepreneurship and strategic management: Insights from a process study. Management science 29 (12), 1349-1364.

Casadesus-Masanell, R., Ricart, J. E. (2010). From strategy to business models and onto tactics. Long range planning 43 (2-3), 195-215.

Chesbrough, H., Rosenbloom, R. S. (2002). The role of the business model in capturing value from innovation: evidence from Xerox Corporation's technology spin-off companies. Industrial and corporate change 11 (3), 529-555.

Contigiani, A., \& Levinthal, D. A. (2019). Situating the construct of lean start-up: adjacent conversations and possible future directions. Industrial and Corporate Change 28 (3), 551-564.

Demil, B., Lecocq, X. (2010). Business model evolution: in search of dynamic consistency. Long range planning 43 (2-3), 227-246.

Demil, B., Lecocq, X., Ricart, J. E., Zott, C. (2015). Introduction to the SEJ special issue on business models: business models within the domain of strategic entrepreneurship. Strategic Entrepreneurship Journal 9 (1), $1-11$.

Eisenhardt, K. M. (1989). Building theories from case study research. Academy of Management Review 14(4), 532-550.

Eisenhardt, K. M., Graebner, M. E. (2007). Theory building from cases: Opportunities and challenges. Academy of Management Journal 50 (1), 25-32.

Felin, T., Foss, N. J., Ployhart, R. E. (2015). The microfoundations movement in strategy and organization theory. The Academy of Management Annals 9 (1), 575-632.

Fisher, G. (2012). Effectuation, causation, and bricolage: a behavioral comparison of emerging theories in entrepreneurship research. Entrepreneurship: Theory and Practice 36 (5), 1019-1051.

Foss, N. J., Saebi, T. (2018). Business models and business model innovation: Between wicked and paradigmatic problems. Long Range Planning 51 (1), 9-21.

Frankenberger, K., Sauer, R. (2019). Cognitive antecedents of business models: Exploring the link between attention and business model design over time. Long Range Planning 52 (3), 283-304.

Frederiksen, D. L. Brem, A. (2017). How do entrepreneurs think they create value? A scientific reflection of Eric Ries' Lean Startup approach. International Entrepreneurship and Management Journal 13 (1), 169-189. 
Gans, J. S., Stern, S., Wu, J. (2019). Foundations of entrepreneurial strategy. Strategic Management Journal $40(5), 736-756$.

Gershman, S. J., Horvitz, E. J., Tenenbaum, J. B. (2015). Computational rationality: A converging paradigm for intelligence in brains, minds, and machines. Science 349 (6245), 273-278.

Ghezzi, A. (2019). Digital Startups and the adoption and implementation of Lean Startup Approaches: Effectuation, Bricolage and Opportunity Creation in practice. Technological Forecasting and Social Change, 146, 945-960 September 2019: 10.1016/j.techfore.2018.09.017.

Ghezzi, A., Cavallo, A. (2020). Agile Business Model Innovation in Digital Entrepreneurship: Lean Startup Approaches. Journal of Business Research 110, 519-537, March 2020: https://doi.org/10.1016/j.jbusres.2018.06.013

Gigerenzer G, Brighton H. 2009. Homo heuristicus: why biased minds make better inferences. Topics in Cognitive Science 1 (1,: 107-143.

Gigerenzer, G. (2016). Towards a rational theory of heuristics. In minds, models and milieux (pp. 34-59). Palgrave Macmillan, London.

Gigerenzer, G., Hertwig, R., Pachur, T. (2011). Heuristics: The Foundations of Adaptive Behavior: New York: Oxford University Press.

Glaser, B., Strauss, A. (1967). Grounded theory: The discovery of grounded theory. Sociology The Journal Of The British Sociological Association 12, 27-49.

Goldstein, D. G., Gigerenzer, G. (2002). Models of ecological rationality: The recognition heuristic. Psychological review 109 (1), 75-90.

Güttel, W., Loock, M., Mangematin, V., Rauch, M. (2018). Heuristics in Technological Forecasting and Social Change. Technology Forecasting and Social Change, Call for Papers, last accessed on September 18th, 2018 at: https://www.journals.elsevier.com/technological-forecasting-and-social-change/call-forpapers/heuristics-in-technological-forecasting-and-social-change

Handfield, R. B., Melnyk, S. A. (1998). The scientific theory-building process: a primer using the case of TQM. Journal of operations management 16 (4), 321-339.

Hitt, M. A., Ireland, R. D., Camp, S. M., Sexton, D. L. (2001). Strategic entrepreneurship: Entrepreneurial strategies for wealth creation. Strategic management journal 22 (6-7), 479-491.

Li, Q., Maggitti, P.G., Smith, K.G., Tesluk, P.E., Katila, R. (2013). Top management attention to innovation: the role of search selection and intensity in new product introductions. Academy of Management Journal 56 (3), 893-916.

Loock, M., Hacklin, F. (2015). Business modelling as configuring heuristics. In Business models and modelling (pp. 187-205). Emerald Group Publishing Limited.

Loock, M., Hinnen, G. (2015). Heuristics in organizations: A review and a research agenda. Journal of Business Research 68 (9), 2027-2036. 
Martins, L. L., Rindova, V. P., Greenbaum, B. E. (2015). Unlocking the hidden value of concepts: A cognitive approach to business model innovation. Strategic Entrepreneurship Journal, 9, 99-117.

Massa, L., Tucci, C. L. (2013). Business model innovation. The Oxford handbook of innovation management 20 (18), 420-441.

Massa, L., Tucci, C. L., Afuah, A. (2017). A critical assessment of business model research. Academy of Management Annals 11 (1), 73-104.

Mathias, B. D., Williams, D. W., Smith, A. R. (2015). Entrepreneurial inception: The role of imprinting in entrepreneurial action. Journal of Business Venturing 30 (1), 11-28.

McDonald, R. M., Eisenhardt, K. M. (2019). Parallel play: Startups, nascent markets, and effective businessmodel design. Administrative Science Quarterly 65 (2), 483-523: https://doi.org/10.1177/0001839219852349

Meredith, J. (1998). Building operations management theory through case and field research. Journal of Operations Management16 (4), 441-454.

Minniti, M., Bygrave, W. (1999). The microfoundations of entrepreneurship. Entrepreneurship Theory and Practice 23 (4), 41-52.

Nambisan, S. (2017). Digital entrepreneurship: Toward a digital technology perspective of entrepreneurship. Entrepreneurship Theory and Practice 41 (6), 1029-1055.

Nelson, R., Winter, S. (1982). An evolutionary theory of economic change. Cambridge, Ma: Harvard University Press.

Newell A, Simon HA. (1972). Human Problem Solving. Prentice Hall: Englewood Cliffs, NJ, USA.

Ocasio, W. (1997). Towards an attention-based view of the firm. Strategic Management Journal 18 (Summer Special Issue), 187-206.

Osiyevskyy, O., Dewald, J. (2015). Explorative versus exploitative business model change: The cognitive antecedents of firm level responses to disruptive innovation. Strategic Entrepreneurship Journal 9, 58-78.

Osterwalder, A., Pigneur, Y. (2010). Business model generation: a handbook for visionaries, game changers, and challengers, John Wiley \& Sons.

Popper, K. (1992). 7. Simplicity. The Logic of Scientific Discovery (2nd ed.). London: Routledge:121-132.

Rappa, M. (2001). Business models on the web. Managing the Digital Enterprise, on-line guide, North Carolina State University (2001), last accessed on September 18th, 2018 at: http://digitalenterprise.org/models/models.html.

Roessler, M., Velamuri, V. K., and Schneckenberg, D. (2019). Corporate entrepreneurship initiatives: Antagonizing cognitive biases in business model design. R\&D Management 49 (4), 509-533.

Saldaňa, J. (2009). The coding manual for qualitative researchers. Lontoo: SAGE Publications Ltd. 
Sarasvathy, S. D. (2001). Causation and effectuation: toward a theoretical shift from economic inevitability to entrepreneurial contingency. Academy of Management Review 26 (2),243-263.

Shane, S. Venkataraman, S. (2000). The promise of entrepreneurship as a field of research. Academy of management review 25 (1), 217-226.

Siggelkow, N. (2007). Persuasion with case studies. Academy of management journal 50 (1), 20-24.

Silva, D. S., Ghezzi, A., de Aguiar, R. B., Cortimiglia, M. N., \& ten Caten, C. S. (2019). Lean Startup, Agile Methodologies and Customer Development for business model innovation. International Journal of Entrepreneurial Behavior \& Research, forthcoming: https://doi.org/10.1108/IJEBR-07-2019-0425

Simon, H. A. (1947). Administrative Behavior: a Study of Decision-Making Processes in Administrative Organization (1st ed.). New York: Macmillan.

Smith, V. L. (2007). Rationality in economics: Constructivist and ecological forms: Cambridge University Press.

Strauss, A., Corbin, J. (1998). Basics of Qualitative Research: Techniques and Procedures for Developing Grounded Theory, 2d ed. Thousand Oaks, CA: Sage.

Teece, D. J. (2018). Business models and dynamic capabilities. Long Range Planning 51 (1), 40-49.

Teece, D.J. (2010). Business models, business strategy and innovation. Long range planning 43 (2), 172-194.

Tversky, A., Kahneman, D. (1975). Judgment under uncertainty: Heuristics and biases Utility, probability, and human decision making (pp. 141-162): Springer.

Walsham, G. (1995). Interpretive case studies in IS research: nature and method. European Journal of information systems 4 (2), 74-81.

Yang, X., Sun, S. L., Zhao, X. (2019). Search and execution: examining the entrepreneurial cognitions behind the lean startup model, Small Business Economics 52 (3), 667-679.

Yin, R. K. (1984). Case study research: design and methods, Applied social research methods series. Thousand Oaks, CA: Sage Publications, Inc.

Zott, C., Amit, R. (2007). Business model design and the performance of entrepreneurial firms. Organization science 18 (2), 181-199.

Zott, C., Amit, R., Massa, L. (2011). The business model: recent developments and future research. Journal of management 37 (4), 1019-1042. 